\title{
Market and political power interactions in Greece: an empirical investigation
}

Tryphon Kollintzas ${ }^{1,2^{*}}$ (D) Dimitris Papageorgiou ${ }^{3}$, Efthymios Tsionas ${ }^{1,4}$ and Vanghelis Vassilatos ${ }^{1}$

\footnotetext{
* Correspondence: kollintzas@hol.gr ${ }^{1}$ Athens University of Economics and Business, Athens, Greece ${ }^{2}$ CEPR, London, UK Full list of author information is available at the end of the article
}

\begin{abstract}
In this paper, using a dynamic panel of 21 OECD countries, we find that, unlike the other OECD countries in the sample, wage setting institutions, competition conditions, public finances, and external imbalances can account for the behavior of the public sector wage premium (WPR) and the self-employed taxation gap (TSL) in Greece and to a lesser extent in Spain and Portugal, in a manner that is consistent with an "insider-outsider society" (IOS). That is, a politicoeconomic system characterized by groups of selfish elites that enjoy market power but at the same time cooperate in influencing government in protecting and promoting their collective self-interests. Then, we find that for Greece as well as Spain and Portugal, WPR and TSL have an adverse effect on both TFP and output growth. Finally, the effect of WPR and TSL on the business cycle (shock propagation mechanism) is investigated via a panel VAR analysis. Again, impulse response function analysis suggests that the shock propagation mechanisms of WPR and TSL for Greece and to a lesser extent for Spain and Portugal are quite different from the rest of the OECD countries. For example, in Greece, unlike the other OECD countries in the sample, a positive temporary shock in WPR causes TFP and output to fall and the public and current account deficits to increase. We take the TFP/output growth and the shock propagation mechanism results to provide strong evidence that Greece and to a lesser extent Spain and Portugal behave like IOS. For that matter, these results are important in order to understand the Greek crisis.
\end{abstract}

JEL classification: J44, J45, O43, O47, O57, P16

Keywords: Labor market institutions, Political institutions, Public sector wage premium, Self-employed taxation gap, Growth, Business cycles, Greek crisis

\section{Introduction}

The motivation for this paper is the apparent divergence in the GDP per capita path of Greece relative to the OECD average, starting about 40 years ago, depicted in Fig. 1a. This divergence relates to both the long-term growth as well as the business cycle. The divergence in the long-term growth pattern is illustrated in Fig. 1b, whereby the HP filter trend component of real per capita GDP is plotted for Greece and the OECD. And, the divergence in the business cycle is illustrated in Fig. 1c whereby the HP filter cyclical component of real per capita output is shown to be very volatile and persistent in Greece, while lagging procyclically relative to the OECD. ${ }^{1}$ Moreover, as strikingly shown in Fig. 1, the recent recession plaguing most OECD countries has been

(c) The Author(s). 2018 Open Access This article is distributed under the terms of the Creative Commons Attribution 4.0 International License (http://creativecommons.org/licenses/by/4.0/), which permits unrestricted use, distribution, and reproduction in any medium, provided you give appropriate credit to the original author(s) and the source, provide a link to the Creative Commons license, and indicate if changes were made. 


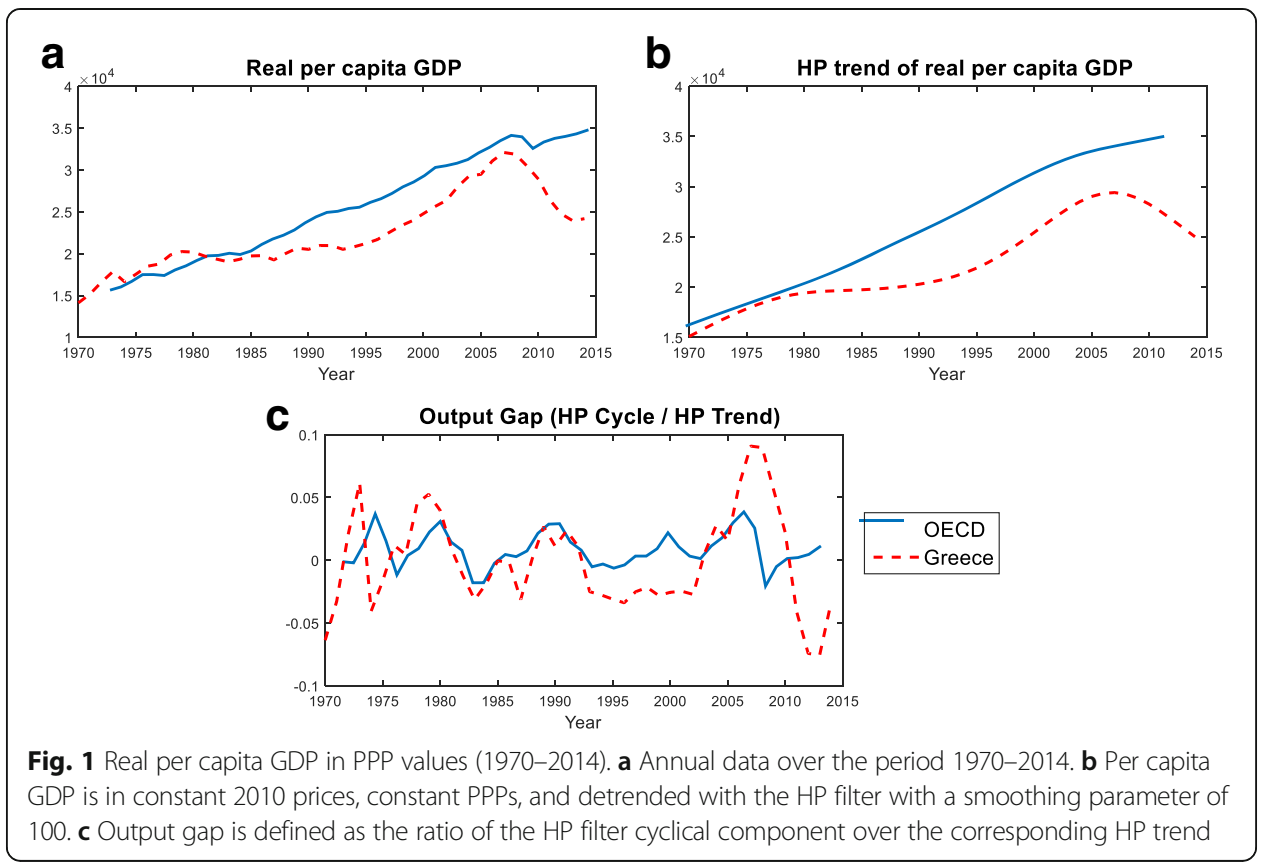

considerably more severe in Greece than in the OECD. Over the last 8 years (2008-2014), the cumulative percentage GDP change in Greece and the OECD average has been - 27 and $+2 \%$, respectively. ${ }^{2}$ So, the obvious question is: Why are these phenomena happening? And, how can they be stopped?

In this paper, we follow the assessments of influential economists such as Olivier Blanchard (2012, 2015) and Edmund Phelps (2015) and seek answers to these questions in the way the Greek politicoeconomic system is organized and, in particular, the way it affects the country's total factor productivity. ${ }^{3}$

In a precursor and a companion to this paper Kollintzas et al. ((2012) and (2017), respectively) proposed a theory that explains the dismal behavior of Greece's GDP per capita path, over the last four decades, as well as the economic crisis plaguing presently its economy. According to this theory, the politicoeconomic system of Greece is the main culprit. In essence, since the re-establishment of democracy in 1974, Greece developed its own brand of capitalism. Although this initially may have helped the country grow, this eventually handicapped and finally jeopardized its ability to grow as well as its ability to deal with the sovereign debt crisis that broke out in 2010. This happened because the politicoeconomic system that emerged had two remarkable features: First, it allowed for the creation and operation of certain groups of economic agents we shall refer to as "elites" or "insiders." These insiders enjoyed considerable market and/ or political power. Examples of main groups of insiders are civil servants and employees of public sector corporations (i.e., the so called " $\triangle \mathrm{EKO}$ ") as well as professionals of certain sectors, organized in powerful unions and professional associations, respectively. Second, although each group of insiders behaved independently in the market for its labor services (i.e., ignoring the effects of its actions on the other groups of insiders and society as a whole), it, nevertheless, cooperated with all other groups of insiders within the dominant political parties and government so as to influence government decisions. We refer to this politicoeconomic system as the "insider-outsider 
society" or simply IOS. ${ }^{4}$ The main consequence of IOS is to lower the growth rate of total factor productivity (TFP) and in extreme cases to lower even the level of TFP.

The workings of IOS, that could at the same time serve as a narrative of what actually happened in Greece, may be summarized as follows: In non-competitive markets, the powerful civil servant and public corporation unions succeed in securing very high wages and incomes for their members. These wages lead, in turn, to very high prices for all state services (e.g., law and order, licensing, utilities, and almost all basic networks (e.g., power, water and sewage, phone, garbage disposal, rail, sea transport, oil refineries, natural gas)). The latter are both basic inputs in the economy's production process. Hence, this implies important factor allocation distortions that jeopardize total factor productivity and overall competitiveness. In competitive, by their very nature, markets, economic power is expressed through market regulation in such a way as to ensure minimum compensations and preferential tax treatments for the members of important professional associations (e.g., doctors, lawyers, notaries, engineers, pharmacists). These closed professions are typically unionized and limit entry into their ranks, through a variety of institutional barriers to labor mobility. Most importantly, however, they enjoy special tax privileges that enables them to avoid taxes. Minimum compensations work like the wages in the public sector and $\triangle \mathrm{EKO}$ and preferential tax treatments increase disproportionally the tax burden of outsiders, leading likewise to lower total factor productivity and increased production costs throughout the economy. At the same time, the major political parties and government are influenced by the powerful unions and professional associations. In such a way, these elites cooperate in the governance of the country to ensure their interests (e.g., financing wages and salaries, develop and maintain the underlying public infrastructure and obtain favorable market restrictions and tax exemptions). But all this results in relatively high taxes and/or budget deficits and government borrowing. This leads to further distortions in the economy, further reducing total factor productivity, output, and growth. In relatively low stages of development, the advent of IOS may promote growth. However, as the power of insiders grows stronger, the detrimental effect of the abovementioned distortions becomes dominant. At such a point, the stronger the power of insiders, the lower is the level of TFP.

To comprehend the particularity of the Greek case, it is worth noting that such a strategic interdependence does not happen in Anglo-Saxon countries, because there, unions / professional associations have little power. And, does not happen in the Scandinavian countries where, although strong, unions/professional associations work together, thereby taking account of possible negative effects of their decisions on the whole of society.

It is then this decrease in total factor productivity stemming from both market and fiscal policy distortions that explains the "low flight" of the Greek economy over the past 40 years, as well as the severity of the recession and the ineffectiveness of policies to deal with the crisis.

In this paper, we investigate whether there is formal empirical support for the view that the reason Greece's growth and business cycle behavior is different than the OECD is because its politicoeconomic system behaves like the insider-outsider society of the theory, unlike that of most OECD countries. Obviously, in order to do this, we need to identify variables that can serve as indicators of the degree a real world 
politicoeconomic system behaves like the insider-outsider society of the theory. Our empirical strategy approach then is threefold. At a first stage, we review what the literature suggests as being the basic determinants of the behavior of these IOS indicator variables and split these determinants into two broad categories, namely those that do and those that do not directly relate to our IOS theory. Once we establish that the IOS indicator variables have a different behavior in Greece relative to other countries, we investigate whether these differences remain, once the first group of determinants not related with the IOS explanation are taken into account. Since the answer is positive, we then investigate whether these differences can be accounted for by the second group of determinants that directly relate to the IOS explanation. At the second stage of our empirical investigation, we examine the relationship of these IOS indicators with total factor productivity, output, and output growth. Finally, in the third stage of our empirical investigation, we analyze the business cycle implications of the IOS indicator variables.

More specifically, in this paper, we identify certain public finance features of Greece that make this country stand out among a representative group of OECD countries. And, we connect these features to the dismal behavior of its GDP per capita path, over the last four decades, as well as its present crisis. Specifically, Greece stands out among OECD countries having the highest public sector wage premium, defined as the ratio of the average wage in the public relative to the private sector (WPR). In addition, Greece stands out among OECD countries having the lowest self-employed taxation gap, defined as the ratio of the effective tax rate on the income of the self-employed over labor income (TSL). High values of the public sector wage premium might be related to the influence exerted by public sector employees organized in powerful unions. And, low values of the self-employed taxation gap might be related to the influence exerted by self-employed, organized in powerful professional associations. According to the theoretical work of Kollintzas et al. (2017), these features may be indicative of an "insider-outsider society," whereby the politicoeconomic system is characterized by groups of selfish elites that enjoy market power but at the same time cooperate in influencing the government, in order to maintain and promote their privileges over the rest of the society. Their theoretical model incorporates the insider-outsider labor market structure of Lindbeck and Snower (2001) and the concept of an elite government of Acemoglu (2006). The combination of these two concepts has important implications for the workings of the economic and political systems and leads to labor misallocation and inefficient fiscal policies. The latter two, in turn, are associated with low total factor productivity (TFP) and output growth.

Running panel regressions, we find substantial evidence that the relationship between WPR and TSL and a number of explanatory variables commonly used in the literature is different in Greece relative to other OECD country groups and most importantly that these differences are consistent with the IOS theory. In particular, we show that, unlike the other OECD countries, explanatory variables related to wage setting institutions, competition conditions, public finances, and external imbalances can account for the behavior of WPR and TSL in Greece and to a lesser extent in Spain and Portugal, in a manner that is consistent with insider-outsider society theory. Thereby, we establish that WPR and TSL are likely candidates as proxies for the strength of the insider-outsider society. 
Then, we proceed to investigate the role of WPR and TSL for the behavior of TFP and output growth. In doing so, we regress each one of these variables on TFP. And, we run Barro regressions incorporating WPR or TSL in the list of explanatory variables commonly used by this literature. We find that for Greece as well as Spain and Portugal, WPR and TSL have an adverse effect on both TFP and output growth. Finally, the relationship between these variables and the business cycle (shock propagation mechanism) is investigated via a panel VAR analysis. Again, the impulse response function (IRF) analysis suggests that the shock propagation mechanisms of both WPR and TSL for Greece and to a lesser extent Spain and Portugal are quite different from the rest of the OECD countries. For example, in Greece, unlike the other OECD countries, a positive temporary shock in WPR causes TFP and output to fall and the public and current account deficits to increase. We take both (i.e., the TFP/output growth and the shock propagation mechanism) results to provide strong evidence that Greece and to a lesser extent Spain and Portugal behave like the insider-outsider society of the theory.

This paper relates to the literature on the causes and remedies of relatively low growth of per capita GDP in Greece. In particular, it shares with the growth accounting studies of Dimelis et al. (1997), Bosworth and Kollintzas (2002), Kollintzas et al. (2012), Gogos et al. (2014), and Leounakis and Sakellaris and (2014) the result that TFP is to blame for this low growth outcome. It is also consistent with the result of Sondermann (2012) that TFP growth in Greece and Portugal falls behind that of the other Euro Area countries. Further, this paper shares with Alogoskoufis (1995) the view that the low TFP growth in Greece was a consequence of the "bad institutions" that characterized the politicoeconomic system developed after 1974 .

The economics profession largely regards the Greek crisis as a sovereign debt crisis, manifested in the high and unsustainable levels of the debt to GDP ratio in the sense of Reinhart and Rogoff (2010). To this end, this paper relates to the unsustainability issue in two ways. First, by explaining the relatively slow output growth brought about by low TFP growth. Second, by explaining one of the reasons leading to the increase in government deficit and debt, namely, financing government wages and public infrastructure of insiders. ${ }^{5}$ In that sense, this is a contribution to the extensive literature on the Greek crisis. But, with the exception of Ioannides and Pissarides (2015), that also consider the role of market structure and labor institutions, this literature emphasizes other aspects of the causes and remedies of the deep recession. ${ }^{6}$

The rest of the paper is organized as follows. In Section 2, we present the data and study the behavior of WPR and TSL, two variables that capture important features of the insider-outsider society. In Section 3, we examine the importance of WPR and TSL for TFP and long-term growth. In Section 4, we investigate the role of WPR and TSL for the shock propagation mechanism. And, Section 5 concludes.

\section{Data, stylized facts, and a test}

\subsection{The public sector wage premium and the self-employed taxation gap}

Our first task is to identify variables that can serve as indicators of the degree a real world politicoeconomic system behaves like the insider-outsider society of the theory. For that reason, here, we focus on two public finance variables that are in the "heart" of the insider-outsider society theory. These are the public sector wage premium, defined 
as the ratio of the average wage in the public sector over the average wage rate in the private sector (WPR) and the self-employed taxation gap, defined as the ratio of the effective tax rates on the income of the self-employed over labor income (TSL). As it turns out, Greece stands out among OECD countries in both of these variables.

The standard measure for comparing wages across sectors is the average compensation rate. OECD defines the compensation rate in a sector as the ratio of the compensation of employees and the number of employees in that sector. Compensation of employees is defined as the total remuneration in cash or in kind, payable by enterprises to employees in return for work done by the latter, during the accounting period. It includes wages and salaries and employers' social security contributions. The number of employees refers to dependent employment and thus excludes the self-employed. Details for the construction of the public sector wage premium are in the Appendix. Ideally, we would have preferred to work with data on public sector enterprises and on public sector wages by government function. However, to our knowledge, such data are not in general available. ${ }^{8}$

TSL is a ratio of effective tax rates in the spirit of Mendoza et al. (1994). Such effective tax rates provide evidence for the distribution of the tax burden across different sources of income and are defined as the ratios between the revenues from particular taxes and the corresponding tax bases. The effective tax rate paid by the self-employed (i.e., the numerator in TSL) is computed as the ratio of the revenues from the taxation of the self-employment income, augmented to include revenues from social security contributions, over the income of the self-employed. Likewise, the effective tax rate on labor income (i.e., the denominator in TSL) is calculated as the ratio of the labor income taxes paid by the employees plus revenues from social security contributions, over the total labor cost of dependent employment. Details for the construction of the effective tax rates are in the Appendix.

As the bars representing medians in Fig. 2 indicate, public sector wage premia are quite different across our sample of 21 OECD countries. These are Australia (AUS), Austria (AUT), Belgium (BEL), Canada (CAN), Denmark (DNK), Finland (FIN), France (FRA), Germany (GER), Greece (GR), Ireland (IRL), Israel (ISR), Italy (ITA), Japan (JPN), Korea (KOR), Netherlands (NLD), Norway (NOR), Portugal (PRT), Spain (SP), Sweden (SWE), the UK, and the USA. We use annual data that, for the most part, characterize the time period from 1970 to 2010. The selection of the OECD countries considered was made on the basis of data availability alone, with the exception of the non-inclusion of Switzerland. The latter has an unusually small number of public sector employees that makes comparisons with the other countries inappropriate. Data definitions and sources, in detail, are given in Tables 23, 24 and 25 in the Appendix. As already noted, Greece tops the list in Fig. 2, with considerably higher public sector wage premium. Note also that Spain and Portugal also rank very high on this list. ${ }^{9}$

Equally strikingly, as shown in Fig. 3, Greece is characterized by a huge effective tax rate differential between the self-employed and employees (i.e., dependent employment). In particular, the effective tax rate of the self-employed is less than one third when compared to the effective tax rate of employees. As in the case of WPR, Spain and Portugal occupy two of the top five spots in the list of countries with the lowest ratio of the effective tax rate of the self-employed over the effective tax rate of employees.

In order to examine whether Greece's growth and business cycle behavior differs from that of most OECD countries, because its politicoeconomic system behaves like 


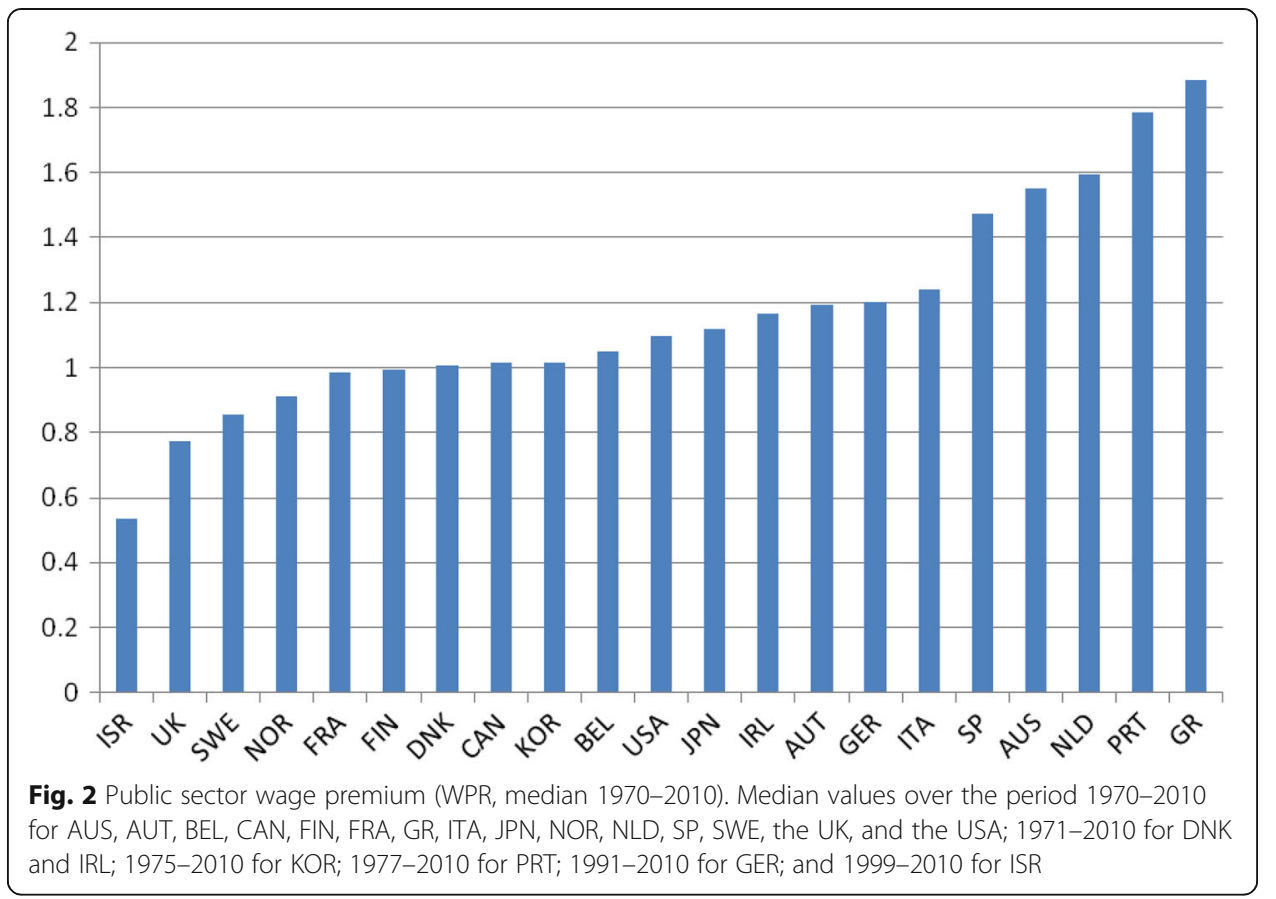

the insider-outsider society of the theory, we consider two control groups: the first is Spain and Portugal (SP) and the second consists of the remaining OECD countries for which the pertinent time series data are available (ROECD). In what follows, for the most part, the ROECD group consists of 18 countries: Australia, Austria, Belgium, Canada, Denmark, Finland, France, Germany, Ireland, Israel, Italy, Japan, Korea, Netherlands, Norway, Sweden, the UK, and the USA. In some cases, as explicitly mentioned, this group consists of fewer countries, depending on data availability.

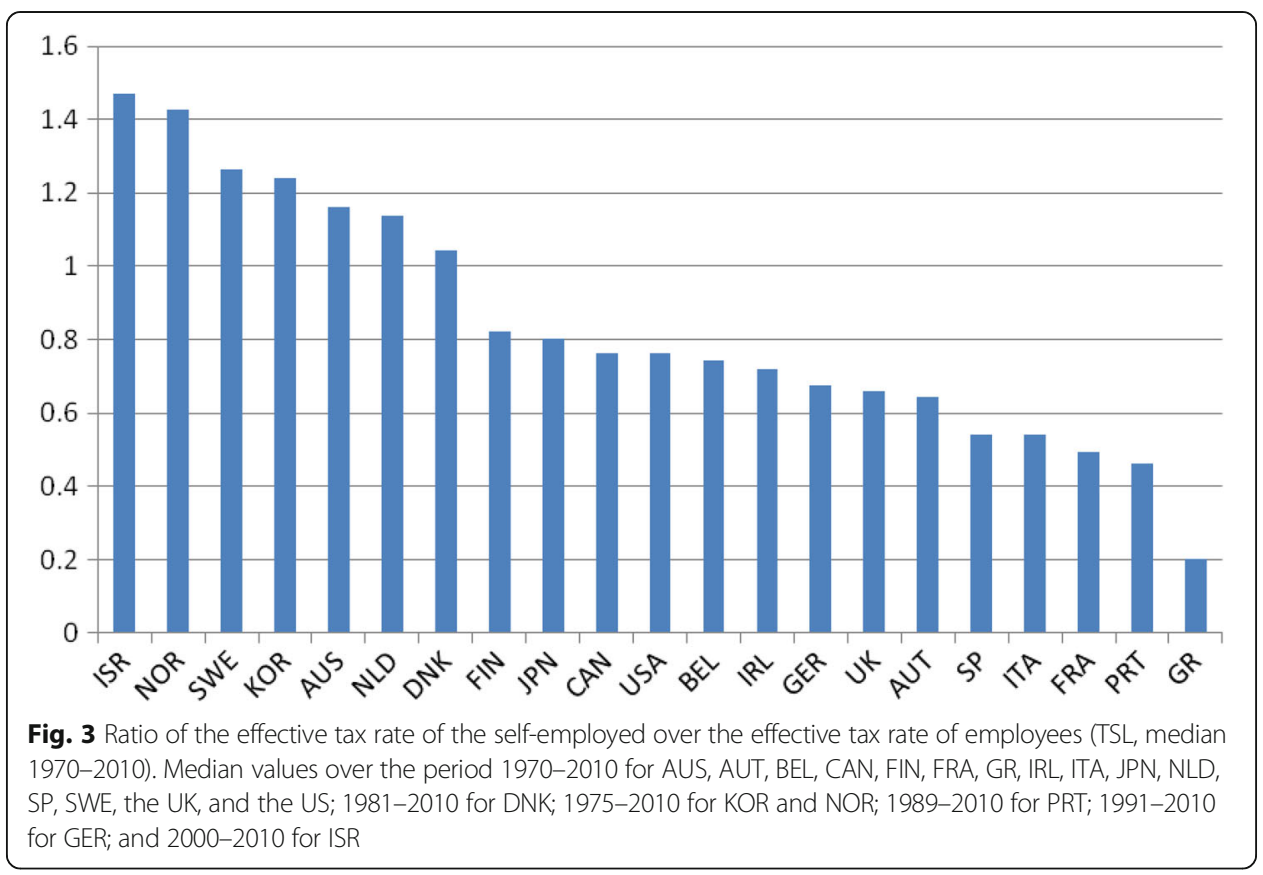


SP may be thought as another control group that, unlike ROECD, apart from the stylized facts pertaining to WPR and TSL (very high wage premium and very low selfemployed tax rate gap), shares, to some extent, with Greece the divergence and crisis severity characteristics, as well. ${ }^{10}$ Moreover, as acknowledged by several authors, they are characterized by similar labor market institutions. And, in particular, as in Greece, the wage setting process in the public sector is characterized by trade union fragmentation and, at the same time, lack of co-ordination. ${ }^{11}$ Also, Greece, Spain, and Portugal share the common characteristic that all labor market (and other) institutions where developed in the mid-1970s after the fall of the respective military regimes and return to democracy. As it turns out, the relationship between WPR and TSL vis-a-vis longterm growth and business cycle are, in general, quite similar between Greece and the SP group and quite different when compared to the ROECD group. Moreover, these similarities and differences are consistent with the view that Greece and to some extent Spain and Portugal are countries organized like insider-outsider societies.

\subsection{What makes Greece different?}

The first question posed is whether WPR (the public sector wage premium) and TSL (the self-employed taxation gap) behave differently in Greece relative to the other OECD countries in the sample. This way, in addition to checking the differences of Greece from ROECD, we can also check whether the differences between SP and ROECD, on the one hand, and Greece and SP, on the other hand, are consistent with IOS theory. We start by estimating the following equations:

$$
Z_{i t}=\alpha_{0}+\mathrm{DUM}^{\prime} \alpha_{1}+u_{i t} ; \quad i=1, \ldots N ; t=1, \ldots, T
$$

where $i$ denotes the country and $t$ the time index, $Z_{i t}$ is either WPR or TSL, $\alpha_{0}$ is a constant, DUM' $=$ [DUMMY_GR, DUMMY_SP] is a pair of dummy variables equal to one for Greece and the SP countries (Spain and Portugal), respectively, $\alpha_{1}$ is a vector of coefficients, and $u_{i t}$ is the error term. Estimates are based on pooled OLS with robust standard errors.

Tables 1 and 2 that consider the two dummies referring to Greece and the SP group as the unique explanatory variables give a positive answer to the abovementioned question. The coefficients of the dummies are positive and significant in the case of WPR and negative and significant in the case of TSL. ${ }^{12}$ These regressions therefore indicate that on average WPR (TSL) are higher (lower) in Greece as well as the SP group. This confirms the stylized facts presented in Figs. 2 and 3.

What lies behind this differentiated behavior of Greece and the SP group vis-à-vis the ROECD group? To answer this, we need first to look at what determines the behavior of WPR and TSL in each group of the countries.

Table 1 WPR vs dummies for Greece and the Spain-Portugal group (SP)

\begin{tabular}{lllll}
\hline Variable & Definition & Coefficient & t statistic & Probability \\
\hline Constant & & 1.097009 & 446.3274 & 0.0000 \\
DUMMY GR & Greece $=1$ & 0.870273 & 25.74714 & 0.0000 \\
DUMMY SP & Spain-Portugal = 1 & 0.574199 & 35.20437 & 0.0000 \\
Adjusted $R$-squared & 0.497914 & & & \\
No. of obs. & 797 & & & \\
\hline
\end{tabular}


Table 2 TSL vs dummies for Greece and the Spain-Portugal group (SP)

\begin{tabular}{lllll}
\hline Variable & Definition & Coefficient & t statistic & Probability \\
\hline Constant & & 0.880478 & 92.07494 & 0.0000 \\
DUMMY GR & Greece $=1$ & -0.61386 & -45.8529 & 0.0000 \\
DUMMY SP & Spain-Portugal $=1$ & -0.43048 & -34.904 & 0.0000 \\
Adjusted R-squared & 0.274175 & & & \\
No. of obs. & 770 & & & \\
\hline
\end{tabular}

There is a large literature on the determinants of the behavior of the public sector wage premium (e.g., Dickens and Katz (1987), Katz and Summers (1989), Gibbons and Katz (1992), Bender (1998), Gregory and Borland (1999), Forni and Giordano (2003), Afonso and Gomes (2008), Gaju et al. (2010), Depalo and Giordano (2011), Giordano et al. (2011), Christopoulou and Monastiriotis (2014), and Campos, et al. (2017)). Following this literature, it is useful to divide these determinants in to six groups: (a) demographic characteristics, (b) the state of the business cycle, (c) labor institutions, (d) competition/regulation conditions, (e) political institutions, and (f) public finances and external imbalances. Our panel data set includes most of the variables encountered in all six categories.

Looking at all these variables, clearly, some may and others may not relate directly to IOS theory. In other words, the above literature occasionally uses variables that we identify as possibly related to IOS, without of course making the underlying connection. What is the profile of the subset of variables that relates to IOS theory? Ideally, this subset should include variables that measure the involvement of government in the economy and especially in basic sectors, union power in these basic sectors, strategic behavior of unions whether private or public, especially the degree of independence from or cooperation with other unions and other government agencies, and most importantly, the degree to which unions internalize the effects of their decisions on the rest of society. In addition, we would be interested in variables that capture the extent of anti-competitive regulations in markets with powerful professional associations. Finally, we would be interested in variables that capture the extent government is influenced/controlled by the various groups of insiders, like the public sector unions and professional associations. Thus, the first two groups, i.e., demographic characteristics and state of the business cycle, contain variables that do not directly relate to IOS theory, while the latter four do relate.

Before considering the variables in detail, it is important to emphasize three points. First, the specific variables considered for our empirical analysis that will be presented below is the product of a compromise between theory and data availability. Second, the variables in the latter four groups may relate to WPR and TSL for other reasons as well that other pertinent theories may suggest. To mention only one from the plethora of examples one can think of, as explained below, the years of democracy might be thought as an indicator of the degree of maturity of an insider-outsider society and thus relate positively with the wage premium and negatively with TSL. On the other hand, however, the years of democracy may indicate better (mature) institutions for societies that have not been plagued by IOS features. Third, when it comes to TSL, there is no empirical literature regarding the determinants of such ratios of effective tax rates. However, the inverse of the tax gap associated with TSL can be equivalently perceived 
as a kind of after tax wage premium enjoyed by the self-employed (associated mainly to professional associations) relative to dependent labor. Consequently, we choose the same set of explanatory variables as in the case of WPR.

Next, we present the explanatory variables used in the empirical investigation and discuss their possible relationship to WPR and TSL. Data sources and definitions in detail are in the Appendix.

2.2.0.1 Demographic factors The percentage of population with age over 25 with completed tertiary schooling (POPT25), the dependency ratio, i.e., people younger than 15 and older than 64 as a share of working age population (DEP_RATIO), and urban population as a share of total population (URBAN_POP). POPT25, a proxy for education, to the extent that public sector employees have more human capital than the rest of the economy, is expected to relate positively with the wage premium. Also, to the extent that urban areas are in general associated with higher wages as there is relative more employment in services and manufacturing, URBAN_POP is expected to relate negatively with the wage premium. Finally, the dependency ratio is an additional control for the impact of demographic characteristics.

2.2.0.2 State of the business cycle The output gap (YGAP). In general, one would expect private sector wages to vary more, relative to public sector wages, over the business cycle.

2.2.0.3 Labor institutions Union membership (UM), defined as the ratio of employees that are trade union members, divided by the total number of employees. The ratio of union density of public sector workers to the union density of private sector workers (UD_RATIO), an index of coordination of wage-setting (COORD); an index of centralization of wage bargaining, taking into account both union authority and union concentration at multiple levels (CENT) ${ }^{13}$ These variables are defined and compiled in the ICTWSS database (see Visser (2013)). The UD_RATIO can be thought of as a proxy of the relative power of the public sector unions. COORD can be thought of as a measure of union cooperation, and CENT can be thought of as a measure of internalization of wage setting externalities. UM can be thought of as a measure of the power of unions, in general. Given our theory, in countries with IOS characteristics, one should expect WPR (TSL) to correlate positively (negatively) with UD_RATIO and negatively (positively) with CENT and CORD. Since UM characterize wage setting in the economy as a whole, and, for example, high UM may be associated with higher wages in both the private and the public sector, its correlation with WPR is not clear. On the other hand, in countries with IOS characteristics, one should expect a negative correlation with TSL: although high UM implies that all unions have relatively high power, still it is professional associations that set tax breaks as their priority.

2.2.0.4 Competition/regulation conditions Regulation index in energy, transport, and communication (index of anti-competitive regulations in the respective product markets, ETCR) and regulation index in legal professional services (PSL). The source for these variables is the OECD Product Market Regulation (PMR) database. ${ }^{14}$ ETCR is an 
indication of public sector involvement in markets, while PSL captures the degree of regulation in professionals' markets. A higher value of both indices is associated with a greater degree of regulation. Obviously, in countries with IOS characteristics, both these variables are expected to positively (negatively) correlate with WPR (TSL).

2.2.0.5 Political institutions The number of years a country has been under a democratic regime (TENSYS); the number of years the governing party has been in office (PRTYIN); the fraction of seats held by the government, i.e., the margin of majority (MAJ). These variables, defined and compiled in the DPI-2012 Database of Political Institutions, may be important in countries that do have IOS characteristics, as they may capture the extent government is influenced/controlled by the various groups of insiders. In such a case, governments with strong majority or parties that stay in office for many years, find conditions more favorable to promote the interest of insiders. Thus, in countries with IOS characteristics, one should expect a positive (negative) correlation with WPR (TSL). In what concerns TENSYS, one would expect, in general, a negative (positive) correlation with WPR (TSL), as many years of democracy may indicate efficient institutions. Moreover, at the same time, countries new to democracy, characterized by inefficient institutions and possibly on the process of establishing IOS characteristics, might exhibit a positive (negative) relationship respectively, as it takes time to build an insider-outsider society once democracy is established. Note that Greece, Spain, and Portugal are three countries where democracy was re-established only in the mid-1970s, while as shown in Figs. 2 and 3, all three share a very high WPR and a very low TSL, compared to the other OECD economies in the sample. Last but not the least, to the extent that a more centralized government structure facilitates the cooperation of insiders in government, the level of centralization versus decentralization of the decision-making process is a valid variable. Information related to this issue is provided in the DPI database, by the variable AUTHOR. This takes the value one when states/provinces have authority over taxing, spending, or legislating and zero otherwise. Indeed, the whole time series for Greece is zero. Actually, among the countries in our sample where this variable is available, Greece is the only one with such behavior. Unfortunately, although Greece again stands out, it is very hard to use this variable, due to its total lack of variability.

2.2.0.6 Public finances and external imbalances The total tax revenues-to-GDP ratio (TAX_Y); the public debt-to-GDP ratio (BY); the VAT efficiency index, i.e., the ratio of the VAT effective tax rate to the standard VAT rate (VEF). And, last but not least, the twin deficits: the Government Deficit to GDP ratio (DEFY) and the Current Account Deficit to GDP ratio (CAY). The first two variables (TAX_Y, BY) are associated with the resources available to IOS in order to finance wages, tax breaks, and maintain and develop the underlying public sector infrastructures. As already mentioned, the insider-outsider society relates to the debt sustainability issue, for it explains chronic public deficits along with relatively low growth. ${ }^{15}$ Also, it relates to the "common pool property" of public finances, whereby there is an inherent bias towards higher government spending (lower tax revenues), due to the externality present in the financing of specific government goods and services (tax cuts). ${ }^{16}$ This externality is generated by the 
fact that those that enjoy the benefits of specific government benefits (tax cuts) are fewer and possibly different than those that pay for these benefits (share the cost of no tax cuts, such as with debt financing). And, as a result, there is higher demand for spending (tax cuts). In a way, the insider-outsider society incorporates the common pool problem, as the reason that an outsider does not react to the insider behavior, is also due to the free rider apathy of those that share the cost of insiders' benefits. VEF is a measure of the efficiency of the tax collection mechanism, related to tax avoidance, especially of professionals' groups. Prima facie, VEF has a dual relationship with IOS. Presumably, to the extent that higher efficiency implies more funds for state coffers, it benefits insiders. On the other hand, if tax inefficiencies are brought about by tax avoidance, this may be an indication of tax avoiding professionals. Finally, the inclusion of CAY and DEFY reflect the link between IOS and twin deficits. As emphasized in Kollintzas et al. (2012), the workings of the insider-outsider society explain the "twin deficits" formation, as a consequence of demand-side as well as supply-side effects. The former depend on the dominance of income and wealth effects on consumption and therefore imports, possibly associated with legal and illegal rents of insiders, over general Ricardian-type effects. The latter are associated with rents of insiders that may or may not be associated with the budget deficit. For example, high wages in heavily unionized public sector enterprises directly affect the budget deficit and at the same time drive up cost of intermediate products to the private sector and put upward pressure on private sector wages, as well. And, high fees in regulated professions (e.g., lawyers, engineers, architects, pharmacists, notary publics, certified accountants) drive up production costs in the non-traded and, worst, in the traded goods sectors, jeopardizing the competitiveness of the economy and therefore reducing exports.

First, in Tables 3 and 4, we examine the importance for the behavior of WPR and TSL of the demographic factors and the state of the business cycle (i.e., the two groups of variables that to not directly relate to IOS theory). That is, they report the estimates of the following equations:

$$
Z_{i t}=\alpha+X_{i t}{ }^{\prime} b+u_{i t} ; \quad i=1, \ldots N ; t=1, \ldots, T
$$

where, $i$ denotes the country and $t$ the time index, $\alpha$ is a constant, $Z_{i t}$ is either WPR or TSL, and $X_{i t}$ is a vector of demographic variables as well as the state of the business cycle. Estimates are based on pooled OLS with robust standard errors.

The next question posed, then, is whether the unexplained part of these regressions still differs among Greece, SP, and the remaining OECD countries (i.e., the ROECD group).

Table 3 WPR vs demographic factors and the state of the business cycle

\begin{tabular}{lllll}
\hline Variable & Definition & Coefficient & $t$ statistic & Probability \\
\hline Constant & & 2.971321 & 24.63760 & 0.0000 \\
POPT25 & Population age 25+ with tertiary education & 0.000177 & 0.149244 & 0.8814 \\
DEP_RATIO & Dependency ratio & -0.013838 & -8.552417 & 0.0000 \\
URBAN_POP & Urban Population & -0.014127 & -17.34860 & 0.0000 \\
YGAP & Output gap & -0.137671 & -0.247987 & 0.8042 \\
Adjusted R-squared & 0.191372 & & & \\
No. of obs. & 797 & & & \\
\hline
\end{tabular}


Table 4 TSL vs demographic factors and the state of the business cycle

\begin{tabular}{lllll}
\hline Variable & Definition & Coefficient & t statistic & Probability \\
\hline Constant & & -0.276354 & -3.932854 & 0.0001 \\
POPT25 & Population Age 25+ with tertiary education & 0.013780 & 8.745445 & 0.0000 \\
DEP_RATIO & Dependency ratio & 0.005761 & 4.696193 & 0.0000 \\
URBAN_POP & Urban Population & 0.008376 & 12.11898 & 0.0000 \\
YGAP & Output gap & -0.220484 & -0.386020 & 0.6996 \\
Adjusted $R$-squared & 0.182806 & & & \\
No. of obs. & 770 & & & \\
\hline
\end{tabular}

To see this, we estimate regressions that combine both the demographic and state of the business cycle variables as well as dummies for Greece and the SP group:

$$
Z_{i t}=\alpha_{0}+\operatorname{DUM}^{\prime} \alpha_{1}+X_{i t}{ }^{\prime} b+u_{i t} ; \quad i=1, \ldots N ; t=1, \ldots, T
$$

Again, estimates are based on pooled OLS with robust standard errors.

Tables 5 and 6 reveal that, despite taking into account for the variables that do not directly relate to IOS theory, the dummies remain positive and significant in the case of WPR and negative and significant in the case of TSL, with the effect associated with Greece being much stronger (around double). Moreover, the comparison of the respective adjusted $R$-squared in Tables 3, 4, 5, and 6 leaves no doubt that, when it comes to WPR and TSL, Greece and the SP group are indeed special cases.

These results prompt us to investigate whether the behavior of WPR and TSL in Greece can be accounted for by the other four groups of variables that directly relate to IOS and whether the way they are related is different among the other country groups.

Figures 9, 10, 11, 12 and 13 in the Appendix present scatterplots relating each one of the variables in the last four groups that directly relate to IOS theory, with WPR and TSL. This exercise serves as a way to elicit stylized facts on the difference between Greece and ROECD countries vis-à-vis these variables. Clearly, in all cases, Greece behaves as an outlier, in the sense that it lies in an extreme position of the scatter plots. ${ }^{17}$ More importantly, this difference is in accordance with the IOS theory. For example, Greece is characterized by particularly high union power in the public sector (UD_RA$\mathrm{TIO})$, excessive product market regulation (ETCR) and excessive regulation in

Table 5 WPR vs demographic factors and the state of the business cycle variables with country dummies

\begin{tabular}{lllll}
\hline Variable & Definition & Coefficient & $t$ statistic & Probability \\
\hline Constant & & 2.212455 & 16.80728 & 0.0000 \\
POPT25 & Population Age 25+ with tertiary education & 0.00193 & 1.739468 & 0.0823 \\
DEP_RATIO & Dependency ratio & -0.00991 & -5.90045 & 0.0000 \\
URBAN_POP & Urban Population & -0.00815 & -10.0033 & 0.0000 \\
YGAP & Output gap & -0.09179 & -0.24855 & 0.8038 \\
DUMMY GR & Greece=1 & 0.821895 & 27.14865 & 0.0000 \\
DUMMY SP & Spain-Portugal=1 & 0.477169 & 19.49924 & 0.0000 \\
Adjusted R-squared & 0.568369 & & & \\
No. of obs. & 797 & & & \\
\hline
\end{tabular}


Table 6 TSL vs demographic factors and the state of the business cycle variables with country dummies

\begin{tabular}{lllll}
\hline Variable & Definition & Coefficient & $t$ statistic & Probability \\
\hline Constant & & 0.185664 & 2.518292 & 0.012 \\
POPT25 & Population age 25+ with tertiary education & 0.012496 & 9.985624 & 0.0000 \\
DEP_RATIO & Dependency ratio & 0.003027 & 2.441981 & 0.0148 \\
URBAN_POP & Urban Population & 0.005068 & 8.001078 & 0.0000 \\
YGAP & Output gap & -0.20367 & -0.47347 & 0.636 \\
DUMMY GR & Greece=1 & -0.58002 & -39.3594 & 0.0000 \\
DUMMY SP & Spain-Portugal=1 & -0.31156 & -15.0143 & 0.0000 \\
Adjusted R-squared & 0.374305 & & & \\
No. of obs. & 770 & & & \\
\hline
\end{tabular}

professional services (PSL), and large public and current account deficits, as well as tax collection inefficiency (low VEF). Interestingly, Greece does not lie in the corners of the scatterplots concerning coordination and centralization in the labor market (COORD and CENT). Note that these scatterplots seem to reveal a non-linear relationship with both WPR and TSL. As far as the wage premium is concerned, it is the Anglo-Saxon on the one hand and the Nordic countries on the other that constitute the two extremes. In Anglo-Saxon countries where wage bargaining is thought, in general, to be competitive and labor unions are thought to play a relatively small role in wage setting, the levels of CENT and COORD are very low. On the other hand, the Nordic countries have very strong unions in both public and private sectors, and the levels of CENT and COORD are very high. ${ }^{18}$ Here, the unions co-operate to internalize the cost to the economy associated with a high wage premium in one industry or sector. Greece along with the other southern European countries which are characterized by high public sector wage premia lie in the middle, with close to sample average levels for both COORD and CENT. Finally, contrary to what one should have expected following our IOS hypothesis that Greece behaves as an IOS country, tax revenues as a share of GDP in Greece are exceptionally low. This may be explained however by tax evasion and tax avoidance, especially by groups considered as insiders, such as professional associations. ${ }^{19}$ This is also clearly reflected in the exceptionally low value of VEF indicating a far from efficient tax collection mechanism. Also, low tax revenues as a share of GDP, in Greece, may also reflect a long established preference of debt over tax financing of government spending.

Now, in the sense of proceeding towards a more thorough specification of the econometric test of the theory, we also run panel regressions incorporating the complete set of explanatory variables. The idea here is to examine whether the overall dependence of WPR and TSL on the set of these variables is different in Greece, as well as the Spain-Portugal group, than in the other OECD countries. And, whether the overall dependence of the explanatory variables on WPR and TSL in the case of Greece is consistent with the hypothesis of Greece being an insider-outsider society. Note that the results from such an exercise are hard to interpret due to the obvious problem with multicollinearity, especially for the subset of explanatory variables that have a direct relationship to the IOS explanation, which as shown above seem to move in the "same" direction (i.e., the direction implied by the IOS hypothesis). 
In any case, we start by introducing two country dummies, one for Greece and one for the Spain-Portugal group, and estimate the following equation using panel least squares:

$Z_{i t}=\alpha+X_{i t}{ }^{\prime} b_{1}+Y_{i t}{ }^{\prime} b_{2}+\operatorname{DUM}^{\prime} X_{i t}{ }^{\prime} \gamma_{1}+\operatorname{DUM}^{\prime} Y_{i t}{ }^{\prime} \gamma_{2}+u_{i t} ; \quad i=1, \ldots N ; \quad t=1, \ldots, T$

where $i$ denotes the country and $t$ the time index, $\alpha$ is a constant, $Z_{i t}$ is either WPR or TSL, $X_{i t}$ is a vector of exogenous variables not directly related to IOS theory (i.e., demographic factors and the state of the business cycle), $Y_{i t}^{j}$ is a vector of exogenous variables directly related to IOS theory (labor institutions, competition/regulation conditions, political institutions, public finances and external imbalances), and DUM' $=[$ DUMMY_GR, DUMMY_SP] is a pair of dummy variables equal to one for Greece and the SP group (Spain and Portugal), respectively. The results of this exercise reveal the existence of autocorrelation problems. ${ }^{20}$ The use of "Panel Fully Modified Least Squares" to address this problem is not possible in the above equation due to the presence of the country dummies. An informative comparison, however, is possible by discarding the country dummies and running the following regression for two groups:

$$
Z_{i t}=\alpha+X_{i t}{ }^{\prime} b_{1}+Y_{i t}{ }^{\prime} b_{2}+u_{i t} ; \quad i=1, \ldots N ; t=1, \ldots, T
$$

The first group consists of Greece along with Spain and Portugal who share to a large extent similarly strong IOS characteristics (GPS) and the second of the remaining OECD countries (ROECD). ${ }^{21}$ The results are presented in Tables 7 and 8 for WPR and TSL, respectively.

Clearly, credence to the IOS theory would be established if in the GPS group, the coefficients of the IOS-related variables identified above are significant, have the "correct" sign, and are quantitatively bigger (i.e., in absolute value) and more significant than the corresponding ones in the ROECD group. Indeed, when it comes to WPR (see Table 7), the groups of variables that are related to IOS such as labor institutions and competition conditions and public finances are significant and, with the exception of ETCR, have the "correct" sign for the GPS group. For all variables whose corresponding parameters are significant in both groups, the parameter values are quantitatively bigger (in absolute terms) in the GPS group, while sign reversals between the two groups occur in the cases of COORD and VEF. This is taken to suggest that the IOS-related variables are doing better when it comes to the group of countries thought to have stronger IOS characteristics. With the exception of COORD and VEF and TAX_Y, similar arguments hold for the case of TSL (see Table 8). Note that VEF and TAX_Y are all taxation-related variables: There seems to be more than our IOS theory behind the way these variables are related to each other.

\section{The TFP and growth implications of WPR and TSL}

In this section, we investigate the relationship between long-term growth and WPR and TSL. As explained above, the major implication of the insider-outsider society is that it adversely affects TFP, output, and output growth. Both WPR and TSL reflect the extent to which an economy has been imbued by the labor misallocation and tax distortions associated with the workings of IOS. ${ }^{22}$ These are stemming from the fact that it is to the interest of all public sector labor unions and professional associations to cooperate so as to influence government and its budget. Therefore, to the extent a 
Table 7 A test of the IOS theory-dependent variable: WPR

\begin{tabular}{|c|c|c|c|c|c|}
\hline Variable & Definition & ROECD & GPS & ROECD & GPS \\
\hline \multirow[t]{2}{*}{ POPT25 } & \multirow{2}{*}{$\begin{array}{l}\text { Population age } 25+\text { with } \\
\text { tertiary education }\end{array}$} & $0.013752^{* * *}$ & $0.056935^{* * *}$ & $0.016376^{* * *}$ & $0.072230 * * *$ \\
\hline & & 21.68738 & 19.33179 & 19.49832 & 16.95067 \\
\hline \multirow[t]{2}{*}{ DEP_RATIO } & \multirow[t]{2}{*}{ Dependency ratio } & $-0.007610^{* * *}$ & $0.015084^{* * *}$ & $-0.007160^{* * *}$ & $0.030255^{* * *}$ \\
\hline & & -18.71470 & 5.556921 & -17.08557 & 10.26010 \\
\hline \multirow[t]{2}{*}{ URBAN_POP } & \multirow[t]{2}{*}{ Urban population } & $-0.002111^{* * *}$ & $0.043615^{* * *}$ & $-0.001064^{* *}$ & $0.068865^{* * *}$ \\
\hline & & -4.954121 & 9.283251 & -2.155844 & 9.549796 \\
\hline \multirow[t]{2}{*}{ YGAP } & \multirow[t]{2}{*}{ Output gap } & $-0.372530^{* * *}$ & $1.215862^{* * *}$ & $-0.439692^{* * *}$ & 0.211226 \\
\hline & & -9.622241 & 8.592253 & -10.13525 & 1.513867 \\
\hline \multirow[t]{2}{*}{ TENSYS } & \multirow[t]{2}{*}{ Years of democracy } & $-0.013166^{* * *}$ & $-0.048215^{* * *}$ & $-0.014542^{* * *}$ & $-0.046499^{* * *}$ \\
\hline & & -27.33816 & -12.54250 & -28.40986 & -9.354322 \\
\hline \multirow[t]{2}{*}{ PRTYIN } & \multirow[t]{2}{*}{ Years a party is in office } & $-0.001374^{* * *}$ & $0.006619^{* * *}$ & $-0.001297^{* * *}$ & $0.007466^{* * *}$ \\
\hline & & -10.59422 & 7.293152 & -8.701355 & 6.463171 \\
\hline \multirow[t]{2}{*}{ MAJ } & \multirow{2}{*}{$\begin{array}{l}\text { Fraction of seats held } \\
\text { by government }\end{array}$} & $0.170186^{* * *}$ & 0.061034 & $0.175584^{* * *}$ & -0.007409 \\
\hline & & 15.97982 & 0.799573 & 14.33033 & -0.081154 \\
\hline \multirow[t]{2}{*}{ UM } & \multirow[t]{2}{*}{ Union membership } & $-0.005021^{* * *}$ & $-0.010502^{* * *}$ & $-0.005557^{* * *}$ & $-0.006180^{* * *}$ \\
\hline & & -18.22230 & -6.046546 & -18.68675 & -2.640103 \\
\hline \multirow[t]{2}{*}{ UD_RATIO } & \multirow{2}{*}{$\begin{array}{l}\text { Public to private sector } \\
\text { union density ratio }\end{array}$} & 0.003153 & $2.481486^{* * *}$ & -0.000402 & $1.016409^{* * *}$ \\
\hline & & 1.643036 & 10.15728 & -0.182166 & 4.738432 \\
\hline \multirow[t]{2}{*}{ COORD } & \multirow[t]{2}{*}{ Wage setting coordination index } & $0.009548^{* * *}$ & $-0.069391^{* * *}$ & $0.009482^{* * *}$ & $-0.061503^{* * *}$ \\
\hline & & 7.948113 & -11.63344 & 6.851676 & -8.593499 \\
\hline \multirow[t]{2}{*}{ ETCR } & \multirow{2}{*}{$\begin{array}{l}\text { Regulation index in energy, } \\
\text { transportation, and communication }\end{array}$} & $-0.078886^{* * *}$ & $-0.075693^{* * *}$ & $-0.077832^{* * *}$ & $-0.020440^{* * *}$ \\
\hline & & -25.50326 & -6.346026 & -25.96991 & -1.638897 \\
\hline \multirow[t]{2}{*}{ VEF } & \multirow[t]{2}{*}{ VAT efficiency index } & $0.131382^{* * *}$ & $-0.130535^{* * *}$ & $0.089619^{* * *}$ & $-0.558684^{* * *}$ \\
\hline & & 11.38263 & -2.280017 & 7.371067 & -8.110368 \\
\hline \multirow[t]{2}{*}{ BY } & \multirow[t]{2}{*}{ Debt to GDP ratio } & $0.000224^{* * *}$ & $0.005003^{* * *}$ & & \\
\hline & & 3.519767 & 9.960387 & & \\
\hline \multirow[t]{2}{*}{ TAX_Y } & \multirow[t]{2}{*}{ Tax revenues to GDP ratio } & & & $0.556429^{* * *}$ & $2.574937^{* * *}$ \\
\hline & & & & 8.381534 & 5.903848 \\
\hline \multicolumn{2}{|l|}{ Adjusted $R^{2}$} & 0.892180 & 0.964101 & 0.892241 & 0.961601 \\
\hline \multicolumn{2}{|l|}{ N. of obs. } & 395 & 71 & 401 & 71 \\
\hline
\end{tabular}

$t$ statistics in italics

$* * * * *$, and ${ }^{*}$ denote significance at the 1,5 , and $10 \%$ level, respectively

country shares the characteristics of IOS, we should expect WPR to relate negatively and TSL to relate positively, with TFP, output, and output growth. ${ }^{23}$

\subsection{TFP}

The IOS implications for TFP are illustrated in Table 9, whereby, we compare the behavior of Greece to the other countries in the sample. In particular, we would be interested to ascertain whether Greece is different and if any observed differences are consistent with our IOS theory. This table summarizes the following regressions for Greece and the two country groups SP and ROECD ${ }^{24}$ :

$$
\begin{aligned}
& \mathrm{TFP}_{t}^{\mathrm{GR}}=a+b_{1} Z_{t}^{\mathrm{GR}}+\varepsilon_{t}^{\mathrm{GR}} \\
& \mathrm{TFP}_{i t}^{\text {group }}=a+b_{1} Z_{i t}^{\text {group }}+\varepsilon_{i t}^{\text {group }}
\end{aligned}
$$


Table 8 A test of the IOS theory-dependent variable: TSL

\begin{tabular}{|c|c|c|c|c|c|}
\hline Variable & Definition & ROECD & GPS & ROECD & GPS \\
\hline \multirow[t]{2}{*}{ POPT25 } & \multirow{2}{*}{$\begin{array}{l}\text { Population age } 25+\text { with } \\
\text { tertiary education }\end{array}$} & $-0.007635^{* * *}$ & $0.012050^{* * *}$ & -0.000894 & $0.013495^{* * *}$ \\
\hline & & -8.738876 & 9.825228 & -0.784281 & 9.546269 \\
\hline \multirow[t]{2}{*}{ DEP_RATIO } & \multirow[t]{2}{*}{ Dependency ratio } & $-0.002177^{* * *}$ & $-0.006533^{* * *}$ & $-0.003302^{* * *}$ & $-0.006046^{* * *}$ \\
\hline & & -3.775028 & -4.762078 & -5.794885 & -4.688952 \\
\hline \multirow[t]{2}{*}{ URBAN_POP } & \multirow[t]{2}{*}{ Urban population } & $0.021846^{* * *}$ & $-0.003944^{*}$ & $0.021463^{* * *}$ & -0.001165 \\
\hline & & 37.18969 & -1.754419 & 32.32905 & -0.452738 \\
\hline \multirow[t]{2}{*}{ YGAP } & \multirow[t]{2}{*}{ Output gap } & $-0.330004^{* * *}$ & $-0.515270^{* * *}$ & $-0.266744^{* * *}$ & $-0.535301^{* * *}$ \\
\hline & & -6.176525 & -8.926122 & -4.568967 & -11.16596 \\
\hline \multirow[t]{2}{*}{ TENSYS } & \multirow[t]{2}{*}{ Years of democracy } & $-0.004111^{* * *}$ & $0.009931^{* * *}$ & $-0.009989^{* * *}$ & $0.007973^{* * *}$ \\
\hline & & -6.193623 & 6.052335 & -14.48103 & 4.764618 \\
\hline \multirow[t]{2}{*}{ PRTYIN } & \multirow[t]{2}{*}{ Years a party is in office } & $-0.001890^{* * *}$ & 0.000403 & $-0.001415^{* * *}$ & 0.000599 \\
\hline & & -10.54719 & 1.105937 & -7.041950 & 1.587920 \\
\hline \multirow[t]{2}{*}{ MAJ } & \multirow{2}{*}{$\begin{array}{l}\text { Fraction of seats held } \\
\text { by government }\end{array}$} & 0.001660 & -0.052019 & 0.012377 & -0.036235 \\
\hline & & 0.112679 & -1.226267 & 0.747268 & -0.871550 \\
\hline \multirow[t]{2}{*}{ UM } & \multirow[t]{2}{*}{ Union membership } & $-0.007102^{* * *}$ & $-0.009379^{* * *}$ & $-0.006815^{* * *}$ & $-0.008235^{* * *}$ \\
\hline & & -18.12682 & -12.64936 & -16.80220 & -9.794655 \\
\hline \multirow[t]{2}{*}{ UD_RATIO } & \multirow{2}{*}{$\begin{array}{l}\text { Public to private sector } \\
\text { union density ratio }\end{array}$} & $-0.023443^{* * *}$ & $-0.283258^{* * *}$ & $-0.023127^{* * *}$ & $-0.212901^{* * *}$ \\
\hline & & -8.851157 & -2.792456 & -7.761181 & -2.854252 \\
\hline \multirow[t]{2}{*}{ COORD } & \multirow[t]{2}{*}{ Wage setting coordination index } & 0.013865 & $-0.025195^{* * *}$ & $0.013614^{* * *}$ & $-0.025736^{* * *}$ \\
\hline & & 8.238375 & -10.41000 & 7.182157 & -10.77292 \\
\hline \multirow[t]{2}{*}{ ETCR } & \multirow{2}{*}{$\begin{array}{l}\text { Regulation index in energy, } \\
\text { transportation, and communication }\end{array}$} & $-0.015952^{* * *}$ & $0.072124^{* * *}$ & $-0.034958^{* * *}$ & $0.071361^{* * *}$ \\
\hline & & -3.724772 & 15.34342 & -8.670203 & 17.42026 \\
\hline \multirow[t]{2}{*}{ VEF } & \multirow[t]{2}{*}{ VAT efficiency index } & $-0.175460^{* * *}$ & $-0.079611^{* * *}$ & $-0.114566^{* * *}$ & $-0.081259^{* * *}$ \\
\hline & & -10.46235 & -3.394369 & -6.660233 & -3.560441 \\
\hline \multirow[t]{2}{*}{ B_Y } & \multirow[t]{2}{*}{ Debt to GDP ratio } & $-0.000776^{* * *}$ & -0.000148 & & \\
\hline & & -8.705856 & -0.748292 & & \\
\hline \multirow[t]{2}{*}{ TAX_Y } & \multirow[t]{2}{*}{ Tax revenues to GDP ratio } & & & $0.694478^{* * *}$ & $0.262306^{*}$ \\
\hline & & & & 7.507842 & 1.828174 \\
\hline \multicolumn{2}{|l|}{ Adjusted $R^{2}$} & 0.942483 & 0.929550 & 0.944211 & 0.929720 \\
\hline \multicolumn{2}{|l|}{ No. of obs. } & 390 & 69 & 396 & 69 \\
\hline
\end{tabular}

$t$ statistics in italics

$* * * * *$, and * denote significance at the 1,5 , and $10 \%$ level, respectively

Table 9 TFP VS WPR and TSL

\begin{tabular}{llll}
\hline & Greece & SP & ROECD \\
\hline WPR & $-0.258381^{* * *}$ & $-0.047639^{* *}$ & $0.090452^{* * *}$ \\
& -4.849058 & -2.161475 & 8.010170 \\
Adjusted R-squared & 0.892758 & 0.752159 & 0.915153 \\
TSL & $0.516661^{* * *}$ & $0.094088^{* *}$ & -0.039871 \\
& 6.382703 & 2.177210 & -3.729730 \\
Adjusted R-squared & 0.824245 & 0.923985 & 0.907548 \\
\hline
\end{tabular}

$t$ statistics in italics

$*_{* *}^{* *}$, and ${ }^{*}$ denote significance at the 1,5 , and $10 \%$ level, respectively 
where TFPis total factor productivity, $Z$ is either WPR or TSL, and group = SP, ROECD. Trend as an explanatory variable is included as needed. Estimates are based on pooled OLS with robust standard errors. Table 9 summarizes the effects of WPR and TSL on TFP. The regressions in detail are in Tables 15, 16, 17, 18, 19, 20, 21, and 22 in the Appendix. Observe the negative and significant correlation for WPR and positive and significant for TSL in Greece. The SP group shares the same qualitative but quantitatively smaller characteristics with Greece. And, contrary to Greece and the SP group, we observe a positive and significant correlation for WPR and a negative and significant for TSL. These results are in line with the theory, if we take Greece, and to a lesser extent Spain and Portugal, to feature strong IOS characteristics, as opposed to the other OECD countries.

Hence, we take this evidence to suggest that, contrary to what happened in other OECD countries, the observed increases (decreases) of WPR (TSL) in Greece and especially the very high increases from 1980 to 2010 exercised a negative impact on TFP and, therefore, long-term growth (see the graphs of WPR and TSL for Greece in Figure 15 in the Appendix).

\subsection{Barro regressions}

One way to think of the IOS implications for growth is within a neoclassical growth model with endogenous total factor productivity. The latter incorporates the resource allocation distortions associated with the market power enjoyed by each individual group of insiders, as well as the public finance distortions associated with government decisions influenced by all groups of insiders, e.g., distorting taxes and tax breaks, the creation and maintenance of public sector infrastructures for the benefit of insiders. In the previous subsection, we established the important negative effects of both WPR and TSL on TFP for countries where IOS structure is thought to be relevant. Hence, it seems appropriate to investigate the growth dynamics of IOS and by running standard Barro regressions augmented by the inclusion, one at a time, of WPR and TSL. Presumably, countries with strong IOS characteristics will be associated with lower TFP, lower steady-state output, and slower convergence. ${ }^{25}$

More specifically, in order to examine the role of WPR and TSL for output growth, we run Barro regressions of the form:

$$
\gamma_{i t}=a+X_{i t}^{\prime} b+c Z_{i t}+\varepsilon_{i t}
$$

where $\gamma_{i t}$ is the 5-year average growth rate of the real per capita GDP over the period 1975-2010; $X_{i t^{\prime}}$ is a vector of exogenous variables including the log and squared $\log$ of real per capita GDP at the start of each 5 -year period (LNRGDP0 and LNRGDP0^2, respectively), a measure of school attainment at the start of each 5-year period (LNSCH), population growth (POPG), and 5-year period averages of the total investment to GDP ratio (IY), government non-wage consumption as share of GDP (CGNWY) and exports as share of GDP (XY); and $Z_{i t}$ is either WPR or TSL.

Ideally, we would prefer to compare the results from the above regression among, on the one hand, Greece or the Greece, Spain, Portugal group and the remaining group of countries respectively, on the other hand. However, such a Barro regression is not possible for Greece or even the three countries Greece, Spain, and Portugal, due to insufficient number of observations. For that matter, an informative comparison is possible 
by running the Barro regression for two groups: the all-encompassing 21 OECD countries group (OECD21) as opposed to the ROECD group where Greece, Spain, and Portugal are excluded. ${ }^{26}$ Clearly, credence to the IOS theory would be established if in the ROECD group, the coefficients of WPR and TSL are quantitatively smaller and less significant than the corresponding ones in the all-encompassing group.

Tables 10 and 11 summarize the results of each one of the two variables WPR and TSL and the two sample groups. Estimates are based on pooled OLS with robust standard errors over the time period 1975-2010 (5-year averages). These regressions reveal a negative (positive) and significant relationship among WPR (TSL) and output growth in the OECD21 group. In the ROECD group, the respective relationships become quantitatively smaller and clearly less significant. ${ }^{27}$ We take this to suggest that Greece, in particular, and possibly Spain and Portugal have lower growth due to the IOS structure of their respective economies. One should also observe that the $1 \%$ confidence interval of the coefficient of WPR for the OECD21 group does not include the corresponding estimate for the ROECD group. This makes clear that the inclusion of Greece, Spain, and Portugal makes a statistical importance difference. A similar argument holds for TSL.

\section{WPR, TSL, and the shock propagation mechanism}

In this section, our main interest is to (i) trace out the response of key macroeconomic variables to shocks in the two variables that capture the notion of the insider-outsider society WPR and TSL and (ii) to study whether the dynamics of key macroeconomic variables are different across countries with different insider-outsider characteristics. This is done via a VAR model analysis whereby we investigate whether the shock propagation mechanism is different between Greece, the SP group, and the group of the remaining OECD economies (ROECD). We use annual data that cover a maximum time span from 1970 to 2010. We first focus our analysis on Greece. We then estimate a panel-VAR model for the SP and ROECD groups, as well.

In the case of Greece, the VAR specification is:

$$
Y_{t}=A(L) Y_{t}+v_{t}, \quad t=1,2, \ldots, T
$$

while the panel-VAR model is specified as:

$$
Y_{i t}=B(L) Y_{i t}+v_{i t}, \quad i=1, \ldots N ; t=1, \ldots, T
$$

where $L$ denotes the lag operator; $A(L)$ and $B(L)$ are autoregressive lag polynomials; and $Y$ is the five variable vector [TFP, $Z, R G D P, D E F Y, C A Y]$, where $Z$ is either WPR or TSL, $R G D P$ is the log of real per capita GDP, $D E F Y$ is the government budget deficit (Total Government Spending - Total Tax Revenues) as a share of GDP, and $C A Y$ is the current account deficit to GDP as a share of GDP. We think of RGDP, DEFY, and CAY as three variables that summarize the state of the macroeconomy.

Different identification assumptions may imply different qualitative and/or quantitative dynamic responses to shocks. It is important to stress here that what we are interested in is to establish that given the identification choice, the propagation mechanism triggered by an innovation in either WPR or TSL is different in Greece relative to the other country groups and this difference conforms to our IOS theory. Thus, for identification, we follow Love and Zicchino (2006), who also use annual data and moreover conduct an experiment comparing country groups with different 
Table 10 Barro regression including WPR

\begin{tabular}{lllllll}
\hline & OECD21 & & \multicolumn{7}{l}{ ROECD } \\
\hline Variable & Coefficient & Std. error & Probability & Coefficient & Std. error & Probability \\
Constant & 0.183655 & 0.073067 & 0.0132 & 0.178464 & 0.075061 & 0.0192 \\
LNRGDP0 & -0.024161 & 0.009390 & 0.0112 & -0.020463 & 0.009742 & 0.0380 \\
LNRGDP0^2 & 0.001028 & 0.000366 & 0.0058 & 0.000898 & 0.000384 & 0.0213 \\
LNSCH & -0.004393 & 0.008355 & 0.6000 & -0.014039 & 0.008115 & 0.0865 \\
POPG & 0.182955 & 0.124038 & 0.1426 & 0.345050 & 0.147653 & 0.0213 \\
CGNWY & -0.207624 & 0.059525 & 0.0007 & -0.212384 & 0.064097 & 0.0012 \\
IY & 0.019696 & 0.044627 & 0.6597 & 0.001202 & 0.049856 & 0.9808 \\
XY & 0.021071 & 0.010467 & 0.0462 & 0.019419 & 0.010478 & 0.0665 \\
WPR & -0.010768 & 0.003287 & 0.0013 & -0.005286 & 0.003222 & 0.1038 \\
Adjusted $R$-squared & 0.255474 & & & 0.315726 & & \\
No. of obs. & 140 & & & 119 & & \\
\hline
\end{tabular}

characteristics. The identification scheme is based on a Choleski orthogonalization of the shocks. This recursive identification approach assumes that variables that appear earlier in the ordering affect the subsequent variables contemporaneously and with a lag, while variables that come later affect the previous ones only with a lag. Hence, variables that appear earlier in the VAR are "more exogenous" than the ones that come later. Thus, according to our specification, an innovation in $Z$ (that is, either WPR or TSL) has a contemporaneous effect on all variables in the VAR with the exception of the preceding TFP. That is, after TFP, $Z$ is considered as the second "most exogenous" variable in the system, an assumption that is consistent with our analysis. This assumption is consistent with our theory's predictions that it takes some time for the IOS to establish and its effects on the economy's productivity to be set in action. We also allow the government budget deficit-to-GDP ratio to be contemporaneously affected by the real per capita GDP, since components of government spending and revenues, such as government transfers and income taxes, are likely to depend on the current level of economic activity (see also Blanchard and Perotti (2002) and Kim

Table 11 Barro regression including TSL

\begin{tabular}{lllllll}
\hline & OECD21 & & & ROECD \\
\hline Variable & Coefficient & Std. error & Probability & Coefficient & Std. error & Probability \\
Constant & 0.292172 & 0.103209 & 0.0054 & 0.291167 & 0.103595 & 0.0059 \\
LNRGDP0 & -0.039826 & 0.013108 & 0.0029 & -0.035637 & 0.013751 & 0.0109 \\
LNRGDP0^2 & 0.001612 & 0.000499 & 0.0016 & 0.001463 & 0.000519 & 0.0057 \\
LNSCH & -0.012931 & 0.009827 & 0.1906 & -0.020727 & 0.009323 & 0.0283 \\
POPG & 0.053776 & 0.121449 & 0.6587 & 0.172883 & 0.100475 & 0.0882 \\
CGNWY & -0.247260 & 0.070307 & 0.0006 & -0.277089 & 0.065104 & 0.0000 \\
IY & -0.033750 & 0.053609 & 0.5301 & -0.048960 & 0.049251 & 0.3224 \\
XY & 0.015889 & 0.012339 & 0.2002 & 0.015728 & 0.012605 & 0.2148 \\
TSL & 0.019319 & 0.008500 & 0.0247 & 0.015058 & 0.008291 & 0.0721 \\
Adjusted $R$-squared & 0.293549 & & & 0.357271 & & \\
No. of obs. & 136 & & & 117 & & \\
\hline
\end{tabular}


and Roubini (2008)). Finally, as in Kim and Roubini (2008), the current account-toGDP ratio is simultaneously affected by all other variables. Each VAR system is estimated by OLS. ${ }^{28}$

\subsection{TFP}

To fix ideas, we start with the dynamic responses from a positive TFP shock, depicted in Fig. $4 \mathrm{a}-\mathrm{c}$, in order to investigate whether the propagation mechanism arising from a TFP shock differs among groups of countries with different IOS characteristics. Red dashed lines denote the one-standard deviation confidence intervals based on 1000 Monte Carlo simulations.

First of all, the effect of a positive TFP shock on RGDP, DEF/Y, and CA/Y is qualitatively and quantitatively similar irrespective of the VAR vector considered (i.e., either including WPR or TSL or TSELF, respectively). In what concerns RGDP, we observe a positive response throughout and in all country groups, as expected. For that matter, this lowers the public deficit, both directly and indirectly through the automatic stabilizers effect of increased tax revenues. However, the effect is considerably short lived in Greece since, after two periods, the deficit increases. This diverging behavior of Greece relative to ROECD and SP stems from the behavior of WPR.

As can be seen in the second column of Fig. 4, the effect of a positive TFP shock on WPR is actually very different among Greece and the ROECD and SP groups. In Greece, WPR falls in the very short run but eventually increases substantially. On the other hand, in the case of the ROECD group, WPR falls throughout, indicating that the positive TFP shock has a stronger positive effect on the wages in the private sector. The opposite seems to hold in Greece, where apart from the first two periods, it is the public sector wages that increase more. The increase in WPR observed in Greece mitigates the increase in output and at the same time increases government spending and thus the deficit. Recall that, according to the theory discussed in the introduction, an increase in the private sector wages raises public sector wages by more, creating additional frictions that mitigate the increase in output brought about by the positive TFP shock. This distortion will be bigger to the degree that higher wages in the public sector imply distortionary tax increases. This relationship between the wage premium and output will be more apparent in the next experiment where we consider the effects of a shock on WPR.

When it comes to the dynamic response of the current account deficit to GDP ratio, as can be seen from the fourth column in Fig. 4, this differs among the three country groups. A positive TFP shock has a short-lived deterioration in the current account deficit in Greece and no effect thereafter. This deterioration comes as a result of an increase in imports due to the increase in RGDP. Thereafter, the increase in imports is counterbalanced by the effects of increased productivity on foreign investment and exports. On the other hand, the current account deficit in the case of the ROECD group improves in the short run, reflecting the positive productivity effect on investment and exports, but eventually deteriorates once the increased imports effect dominates. This effect is the one that dominates the SP group as well.

A final note on the negative dynamic response of TLS in Greece implies that it is the self-employed that benefit (in terms of taxation) more from the positive technology 


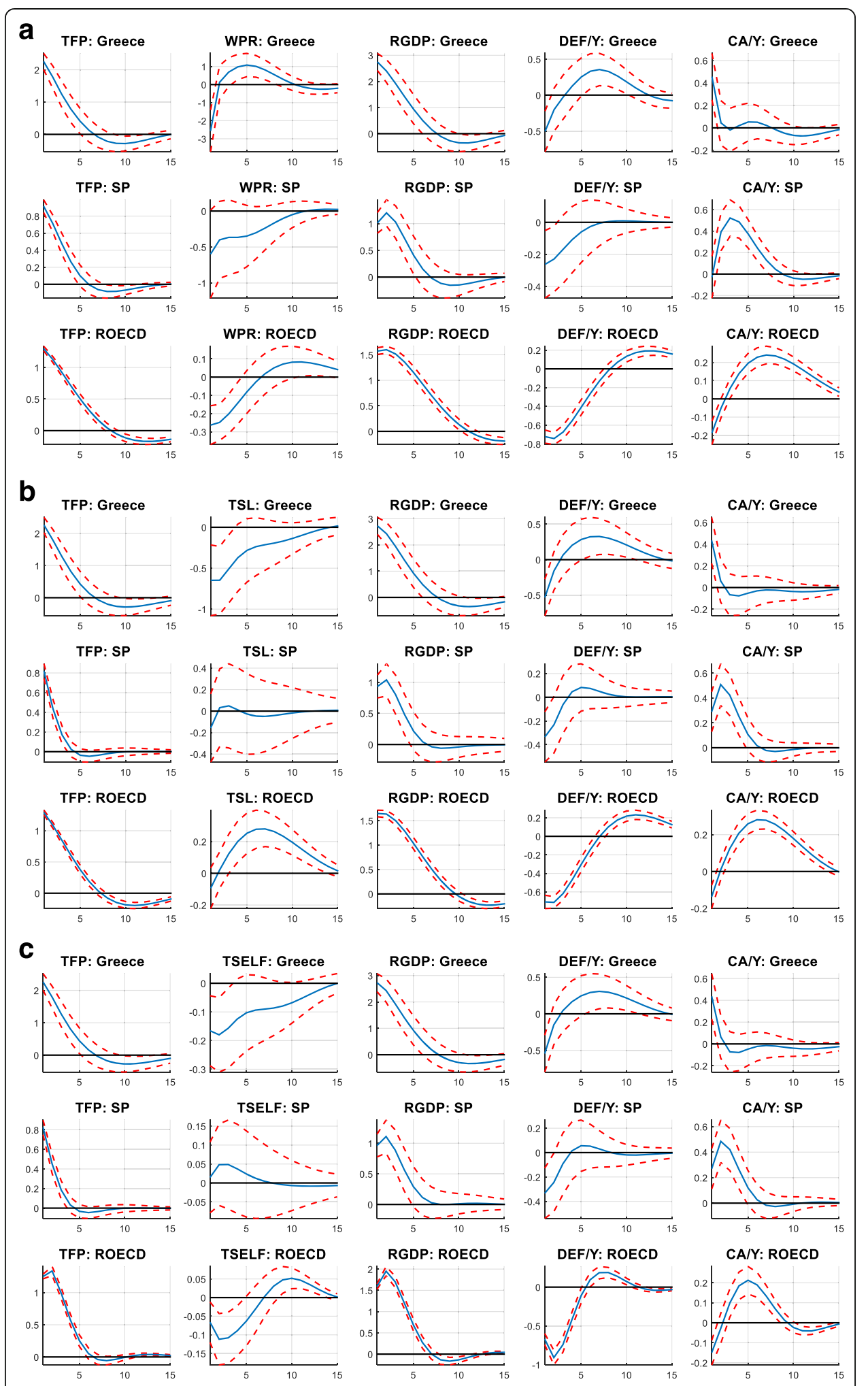

Fig. 4 a Dynamic responses to shock in TFP (vector includes WPR). b Dynamic responses to shock in TFP (vector includes TSL). c Dynamic responses to shock in TFP (vector includes TSELF) 
shock. In order to decipher the effects on TSL, it is helpful to consider first the effects of the productivity shock on the effective tax rate on the income of the self-employed alone (TSELF). As can be seen in Fig. 4c, this is also negative, in Greece. An increase in TFP leads to higher wages, and thus, through the automatic stabilizers, one would expect higher effective tax rates. However, TSELF falls. This reflects the self-employed higher opportunities for tax evasion and tax avoidance, which, as emphasized in the introduction, is a feature of the insider-outsider society. The negative effect on TSL implies that either the tax on labor income increases or fall by less relative to TSELF. When it comes to the ROECD group, TSELF also falls but the overall effect on TSL is positive, implying that increased productivity makes taxes on labor income to fall by more relative to TSELF. In other words, both self-employed and employees benefit from the increase in TFP. This different behavior among the two country groups may be taken as a further indication that the IOS mechanism is at work. Note that the effect on the SP group on both TSELF and TLS is negative but insignificant. It seems that, in all cases, the behavior of the SP group lies somewhere in between Greece and the ROECD group.

\subsection{WPR and TSL}

Figures 5 and 6 display the impulse responses (for the first 15 years) to orthogonal shocks, as well as the one-standard deviation confidence intervals based on 1000 Monte Carlo simulations. Each figure depicts the responses of the endogenous variables to a one-standard deviation shock in a variable thought to capture aspects of IOS, i.e., WPR and TSL, respectively. The first raw, corresponds to Greece, the second to the SP group (Spain and Portugal), and the third to the ROECD group.

Looking at the effects of a shock in WPR, the most striking feature that emerges from the inspection of Fig. 5 is the completely different, both qualitatively and quantitatively, behavior of Greece relative to ROECD. ${ }^{29}$ In particular, for Greece, the increase in WPR lowers TFP, reduces output, and increases both the public and current account deficits (although the effect on the current account is insignificant), while it works in exactly the opposite direction for ROECD. The SP group lies, again, in between Greece and ROECD, with insignificant responses of output and TFP, but significant and

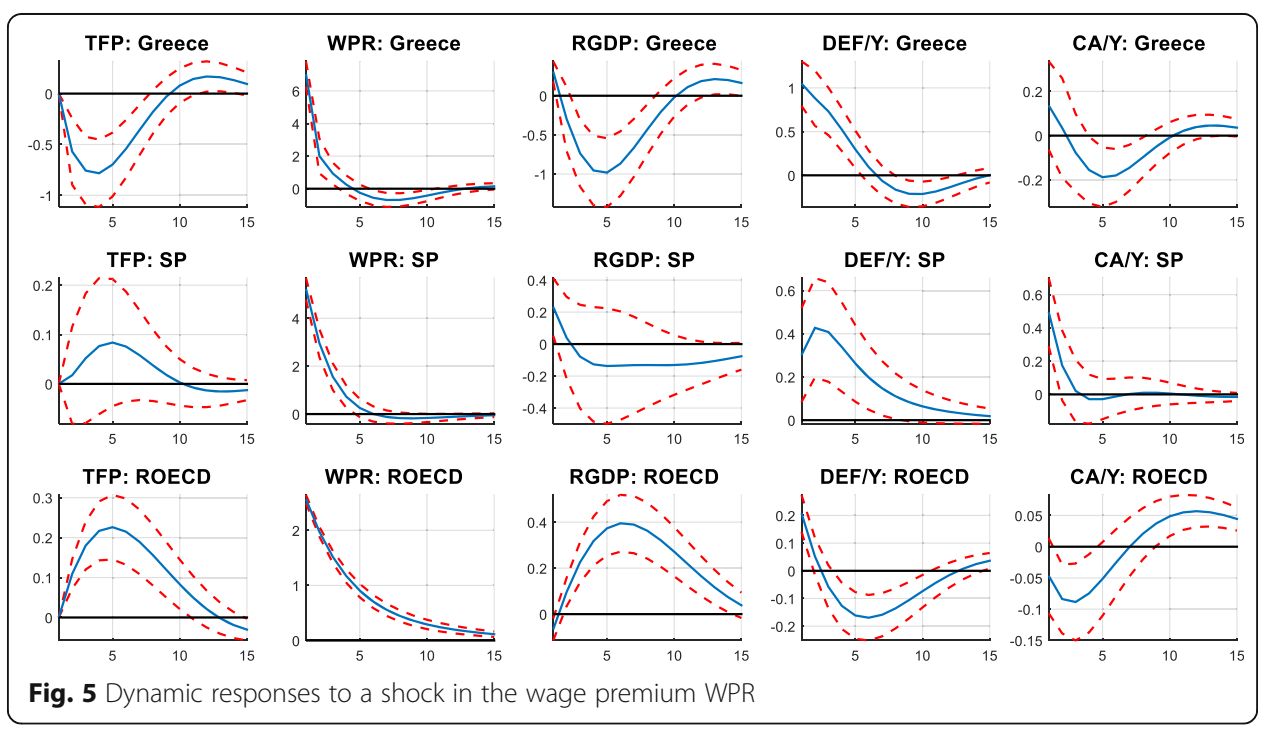




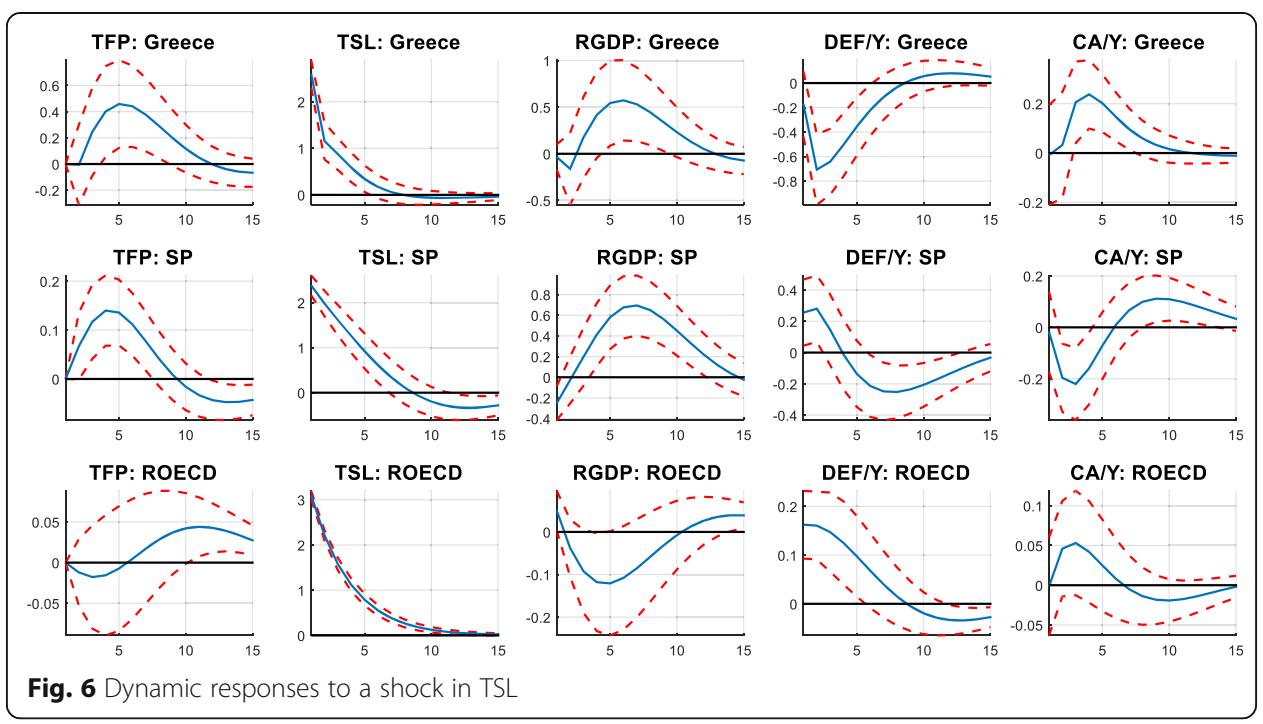

positive for the public and current account deficits. More specifically, the magnitude of the increase in the wage premium in Greece is more than three times bigger relative to the ROECD group and 50 \% bigger relative to the SP group, respectively. This shock, apart from an increase on impact, leads to a significant and long-lasting decrease in Greek RGDP. The increase in the first period may reflect an initially positive demand effect which, however, is quickly counterbalanced by the adverse effects of the IOS propagation mechanism. The latter are reflected in the impulse response of TFP, which reveals a strong negative relationship between WPR and TFP. Concerning the response of DEF/Y, a positive shock in the wage premium gives rise to a big and long-lasting increase in the government budget deficit. On the other hand, the wage premium shock increases the current account deficit but, as already mentioned, the effect is insignificant. These findings are in line with our theory whereby the wage premium affects negatively TFP and therefore output. That is, as our theory predicts, first, a high public sector wage premium is an indication of labor misallocation and tax distortions. And, second, if these frictions are sufficiently strong, both TFP and output decline. On the other hand, in the ROECD group, a shock in WPR is accompanied by a positive effect on TFP and output, a small and quickly vanishing increase in the public deficit, and a small but significant decrease in the current account deficit. It seems that the IOS mechanism is not at work here.

When it comes to the "twin deficits," the behavior of the public and the current account deficits are in accordance with the IOS explanation. This is clearly the case for Spain and Portugal. In what concerns Greece, an increase in WPR stimulates both public and current account deficits. However, the effect on the current account deficit is insignificant. One explanation could be that the increase in the current account deficit brought about by the increase in the government deficit and possibly the fall in exports brought about by the decrease in TFP are counterbalanced by the decrease in the demand for imports stemming from the fall in output. This explanation is also consistent with the fact that in the case of Spain and Portugal, no significant fall in output is observed.

Next, we consider the effects from a shock that increases TSL. These are depicted in Fig. 6. Such a shock shares two features: the first implies a weakening in the IOS 
characteristics, if present. The second has to do with the distortions implied by taxation. ${ }^{30}$ Again, as in the case of WPR, the most striking feature is that Greece is in a league of its own: As a result of a positive shock in TLS, TFP, and RGDP increase, the public deficit falls and the current account deficit increases. On the other hand, the only significant effect in the ROECD group is on the public deficit which rises, while the effects for the SP group are all insignificant. The response of the macroeconomic variables in Greece implies that it is the positive effect on the workings of the economy brought about by the weakening of the IOS characteristics that dominates. Again, these findings are in line with our theory, whereby the inverse of TSL may interpreted as a tax break premium enjoyed by the self-employed over dependent employment. Therefore, an increase in TSL, i.e., a fall in this tax break premium, will be associated with an increase in TFP and output, as observed. ${ }^{31}$

To sum up, our results provide strong enough evidence in support of our IOS hypothesis. In particular, in what concerns the impact of WPR and TSL, Greece, and to some extent Spain and Portugal, behaves in the way predicted by IOS theory: Positive (negative) innovations in WPR (TSL) cause TFP and output to fall and both public and current account deficits to deteriorate. No such behavior emerges for the remaining OECD countries.

\subsection{A corroborating counterfactual}

What if the shock propagation mechanism of WPR and TSL in Greece was qualitatively and quantitatively similar to that of the ROECD groups? The answer is given in Figs. 7 and 8 where the second line reports the impulse response functions for the VAR for Greece wherein the parameter values related to WPR and TSL are substituted by their respective counterparts of the ROECD group VAR. The first line is the same as the first lines in Figs. 5 and 6. Clearly, a shock in WPR has an insignificant case on TFP in the counterfactual experiment contrary to the prolonged negative effect actually observed for Greece. This difference in the behavior of TFP among the actual and the counterfactual IRFs lies behind the corresponding differences in the responses of output and the two deficits. This is in line of course with our view that Greece unlike the ROECD

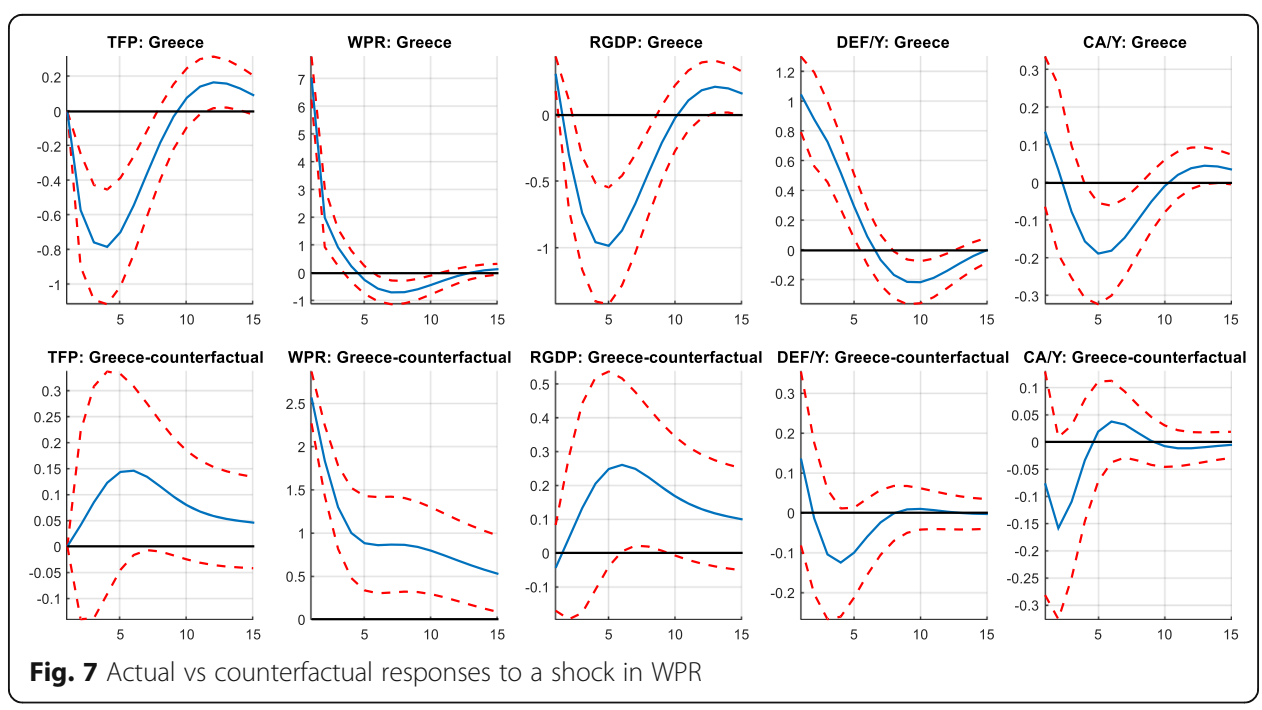




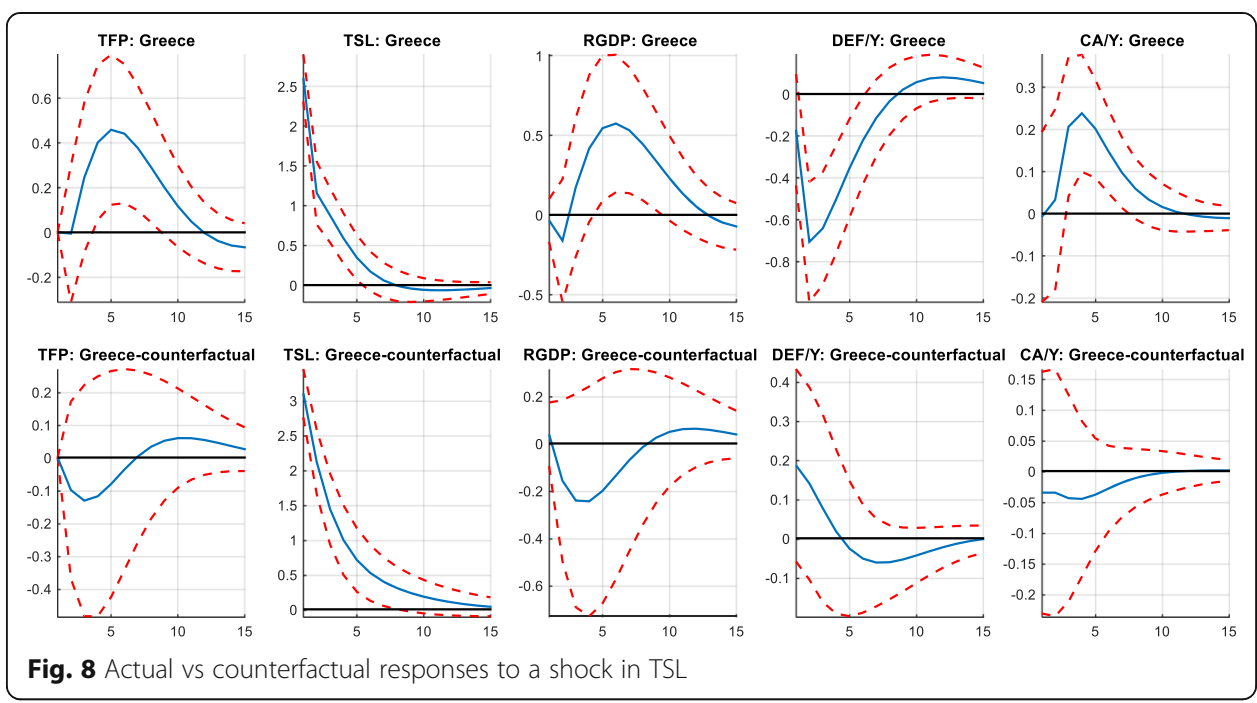

group of countries behaves as an insider-outsider society. A similar picture emerges by comparing the actual and counterfactual responses of a shock in TSL.

\section{Conclusions}

In this paper we identified certain stylized facts of Greek public finances and connected them to the divergence in the GDP per capita path of Greece relative to the OECD average, as well as the economic crisis plaguing Greece, over the last 8 years. These stylized facts are consistent with the "insider-outsider society" politicoeconomic system, characterized by groups of elites with each one of these elites enjoying market power, ignoring the effects of their actions on the rest of society. But, at the same time, all these groups cooperate in influencing government, so as to promote their interests. Greece has the highest ratio of the average wage in the public relative to the private sector and the lowest effective tax rate on the income of the self-employed over labor income, among the group of OECD countries for which the pertinent time series data are available. It was shown that (a) unlike the other OECD countries, the behavior of these variables in Greece, and to a lesser extent in Spain and Portugal, can be accounted for by "insider-outsider society" characteristics associated with, wage setting institutions, competition conditions, tax collection efficiency, and the twin deficits. (b) The behavior of these variables affects long-term growth and the business cycle in Greece in a manner that is similar to Spain and Portugal and quite different than the other OECD countries. Moreover, these differences and similarities are consistent with the "insider-outsider society" explanation.

Taking stock of all these results, we conclude that, indeed, Greece conforms to the IOS structure. And, we take all these results as providing strong evidence that the country's recent dismal growth performance and difficulty in tackling the ongoing and persistent crisis may be due to its politicoeconomic system. If this explanation is correct, the so-called Greek crisis is a structural crisis that was manifested as a sovereign debt crisis. The three rescue packages enacted in 2010, 2012, and 2015 by IMF and the European Institutions focused mainly on fiscal consolidation and dealt with the implementation of structural reforms superficially. What is clearly needed are structural 
reforms to dismantle the insider-outsider society. This, however, requires a thorough look into the organization of Greek society and the workings of the political and economic system. Rents to groups of insiders must be identified, and appropriate policies for their dismantling must be implemented. ${ }^{32}$ Only an appropriately designed program that takes fully into account the idiosyncrasies of Greek society and proposes reforms accompanied with commitment technology mechanisms securing their implementation and perseverance can achieve this. Only such an approach can gain the necessary social support and create well-grounded expectations for getting out of the crisis.

Finally, the results of this paper could be of interest to the European integration question, as countries that have gone beyond a certain point towards the establishment of an insider-outsider society (like Greece and possibly other South European countries) will have a difficulty following the others in TFP and output growth, as already suggested by several policy influential economists (see, e.g., Blanchard (2004), Alesina and Giavazzi (2008)).

\section{Endnotes}

${ }^{1}$ See also Tables 12 and 13 in the Appendix where the second moment properties of the output gap are shown.

${ }^{2} \mathrm{~A}$ similar picture emerges when comparing Greece to the Euro Area average, with the cumulative percentage GDP change in the latter over the same period being $-2.7 \%$ (see Figure 14 in the Appendix). The decade 1996-2006 is a temporary short-lived break to the dismal overall divergent long run picture. Over this period, there is indeed a convergent behavior of Greek GDP. However, this is a period characterized by many factors, e.g., the pre-EMU entry fiscal consolidation efforts, a positive wealth effect associated with the overvaluation of the drachma upon entry, and the Olympic games. All these factors are not related to the frictions implied by the "insider-outsider society" politico-economic explanation we propose. These frictions, discussed and empirically investigated in this paper, existed beforehand and still remain intact. In other words, in the absence of these frictions, the observed convergence would be, most likely, more prominent and sustainable.

${ }^{3}$ In his defense of the 2010 and 2012 debt restructuring programs of Greece that IMF co-sponsored, Olivier Blanchard (2015), IMF's chief economist at the time, argued that: "Given the dismal productivity growth record of Greece before the program, a number of structural reforms were seen as necessary, ranging from a reform of the tax administration, to reduce barriers to entry in many professions, to reforms of pensions, to reforms of collective bargaining, to reforms of the judicial system, etc." And, 2006 Nobel laureate in Economics, Edmund Phelps (2015) argued that: "Too many politicians and economists blame austerity - urged by Greece's creditors - for the collapse of the Greek economy. But the data show neither marked austerity by historical standards nor government cutbacks severe enough to explain the huge job losses. What the data do show are economic ills rooted in the values and beliefs of Greek society. Greece's public sector is rife with clientelism (to gain votes) and cronyism (to gain favors) - far more so than in other parts of Europe." 
${ }^{4} 1974$ is marked by the fall of the military regime in Greece and return to democracy. It is after the subsequent institutional vacuum that most labor market and political institutions in Greece where developed thereafter. Several political analysts have recognized that the two dominant parties that alternated in power since 1974 (i.e, the center right party "New Democracy," founded by Konstantinos Karamanlis and the center left party "PASOK," founded by Andreas Papandreou) were to a great extent controlled by major unions, especially those of the public sector and $\triangle \mathrm{EKO}$, and professional associations. These unions and professional associations were represented in party organization, parliament, and eventually, government. In fact, there are numerous examples where a union or a professional association leader became minister in a ministry that controlled the underlying business sector (see, e.g., Michas (2011), Lygeros (2012) and Doxiadis (2013)). Such an interaction has been emphasized in (i) the "neo-corporatism" political science literature (see, e.g., Schmitter (1977), Sargent (1985), and Cawson (1986)), in general, and (ii) the "variety of capitalism" literature (see, e.g., Molina and Rhodes (2007)) for Southern Europe and Featherstone (2008) for Greece).

${ }^{5}$ This is a manifestation of the common pool property of public finances. See Section 2.2 and the references provided in Endnote 16.

${ }^{6}$ These aspects include debt dynamics (see, e.g., House and Tesar (2015) and Schumacher and Weder di Mauro (2015); external dependence and sudden stop issues (see, e.g., Gross (2013), Reinhart and Trebesch (2015), and Gourinchas et al. (2016)); contagion effects (e.g., Mink and De Haan (2013)), political economy aspects of the policies selected by national, supranational, and international institutions to deal with the crisis (see, e.g., De Grauwe (2013) and Ardagna and Caselli (2014)); bargaining outcomes in dealing with the crisis and the role of austerity (e.g., Zettelmeyer et al. (2013)); and the interaction between external government debt crisis and a bank run prolonging the ensuing recession (e.g., Arellano et al. (2015)). There is also a number of policy discussions highlighting the role of particular institutions for the economic policy effects during the crisis (see, e.g., the postings in VOX by Bulow and Rogoff (2015), Feld et al. (2015), Manasse (2015), and Mody (2015)).

${ }^{7}$ The time series of WPR and TSL for Greece are plotted in Figure 15 in the Appendix. Additional public finance variables that according to insiders-outsiders society theory should adversely affect both growth and the business cycle and at the same time Greece stands out among the Euro Area countries were discussed in Kollintzas et al. (2012). These are the ratio of "General Public Services" and "Economic Affairs" over GDP. The former relates to procurement spending and the latter relates to subsidies. Certain components of both of these types of public spending are considered to be primary targets of special interest groups and political clientelism. Data availability precludes us from considering these variables in our sample.

${ }^{8}$ A cursory look at circumstantial evidence on wages in Greek public corporations $(\triangle \mathrm{EKO})$ indicates that they are much higher compared to public sector wages as well as same sector public corporations in other countries. For example, Table 14 in the Appendix shows evidence on $\Delta \mathrm{EH}$ (the Greek Power Company) 
in 2008 and 2009 (i.e., before the crisis erupted) and the German power company EON (one of the biggest power companies in Europe).

${ }^{9}$ This ranking still emerges from micro-data, as well. See Giordano et al. (2011). The substantial public sector wage premium in Greece is also a feature identified in microdata (see, e.g., Christopoulou and Monastiriotis $(2014,2016)$ ).

${ }^{10}$ Real per capita GDP in Spain and Portugal is plotted in Figure 16 in the Appendix.

${ }^{11}$ See Sections 3.5.2 and 3.9 in European Commission (2013) and Visser (2013). See also Ghenakos (2013) and Vourvachaki (2013) for a recent assessment of product market reforms and wage setting institutions, respectively, in Greece.

${ }^{12} \mathrm{Keep}$ in mind that the higher the wage premium and the lower the TSL ratio, the stronger the IOS characteristics.

${ }^{13}$ Ioannides and Pissarides (2015) focus on the key role of product and labor market reforms (or lack thereof) on the Greek crisis. Gregory and Borland (1999) and Forni and Giordano (2003) emphasize the importance of labor market institutions for the behavior of the public sector wage pemium. In particular, Gregory and Borland include UD_RATIO so as to capture the power of unions in the public sector and Forni and Giordano include early measures of coordination and centralization in the wage setting process so as to capture the degree of cooperation between public and private sector unions.

${ }^{14}$ For the construction of these indices, see Conway and Nicoletti (2006).

${ }^{15}$ This effect has been emphasized in the early literature on sovereign debt sustainability (see, e.g., Giavazzi and Spaventa (1988) and Dornbusch and Draghi (1990)).

${ }^{16}$ See Hallerberg and von Hagen (1999), Hallerberg et al. (2009), von Hagen and Harden (1994), Milesi-Ferretti (2004), Velasco (1999), Kontopoulos and Perotti (1999), and Eichengreen et al. (2011).

${ }^{17}$ The respective regressions with country dummies for Greece and the SpainPortugal group confirming that these countries, especially Greece, are outliers, are available upon request.

${ }^{18}$ See Visser (2013), European Commission (2013) and Kollintzas et al. (2017), for related country clusterings.

${ }^{19}$ There is plenty of evidence on the exceptionally high levels of tax evasion in Greece. See, e.g., Schneider and Buehn (2013). Also, Artavanis et al. (2012) reveal the important role in this respect played by members of professional associations.

${ }^{20}$ The results from regressions using pooled OLS with dummies for Greece and the Spain-Portugal group are available upon request.

${ }^{21}$ Running such a regression is not possible for Greece alone due to insufficient number of observations.

${ }^{22}$ The results of this section complement the findings of other strands of the literature on the role of institutions for business cycles (see e.g., Gnocchi, et al. (2016)) and TFP behavior (see e.g. Angelopoulos, et al. (2009) and Angelopoulos, et al. (2011)).

${ }^{23}$ This is essentially the mechanism suggested by Kollintzas et al. (2017), where WPR is a focal variable. They show that TFP declines with the wage premium, but increases with the size of the public sector, as the "variety" effect dominates over the "labor misallocation" effect. However, the overall effects on steady-state capital, output, and growth towards the steady state, depend on the after-tax 
labor productivity. For it is assumed that the underlying infrastructure, associated with the publicly provided intermediate goods, is financed by a distortionary income tax. Then, it is shown that the effect of an increase in the number of publicly provided intermediate goods on steady-state output and growth towards this steady state is negative (positive), depending on the existing number of publicly provided intermediate goods. If this number is higher or lower than a certain threshold, the combination of the "labor misallocation" and the tax distortion effects dominates over (is dominated by) the "variety" effect. All this being quite plausible, as the "variety" effect ("labor misallocation" and tax distortion effects) decreases (both increase) with the existing number of publicly provided intermediate goods.

${ }^{24}$ ROECD includes AUS, AUT, BEL, CAN, DNK, FIN, FRA, GER, IRL, ITA, JPN, NLD, NOR, SWE, the UK, and the USA. Data for TFP are not available for KOR and ISR.

${ }^{25}$ Kollintzas et al. (2017) establish the channel among TFP and WPR and show the existence of a steady state and convergence therein, as well as the adverse effect of IOS both for long run and transition.

${ }^{26}$ OECD 21 includes AUS, AUT, BEL, CAN, DNK, FIN, FRA, GER, GR, IRL, ISR, ITA, JPN, KOR, NLD, NOR, PRT, SP, SWE, the UK, and the USA.

${ }^{27}$ These results are robust to changes in the length of the sample and inclusion of explanatory variables. Results are available upon request.

${ }^{28}$ Data for Greece cover the period 1970-2010, while data for the panel-VARs cover a maximum time span over 1970-2010 per country. All country variables have been detrended with a linear and quadratic trend. The VAR for Greece and the respective panel-VARs for the two groups are estimated using one lag. ROECD group includes AUS, AUT, BEL, CAN, DNK, FIN, FRA, GER, ITA, JPN, NLD, NOR, SWE, the UK, the USA, and IRL. Data for TFP are not available for KOR and ISR.

${ }^{29}$ Christopoulou and Monastiriotis (2016) find that, contrary to other European countries, public wage sector premia increased during the crisis. This is also evident from Figure 15 in the Appendix: despite a sharp but temporary fall in 2011, reflecting the sharp decline in public sector wages under the first fiscal consolidation program implemented in 2010, WPR quickly returned to its precrisis levels. Also, TSL remains at its pre-crisis levels. The different behavior of Greece as well as Spain and Portugal is also documented by Pérez et al. (2016) who examine the effects of government wage bill reforms in the EU.

${ }^{30}$ TSL increases when the effective tax rate on the income of the self-employed (TSELF) increases by more (or falls by less) relative to the effective tax rate on dependent employment income. Although an increase in TSL implies a weakening in the IOS characteristics, the interpretation of the dynamics is tricky since it is difficult to trace out whither the results stem from: TSL consists of a ratio of distorting taxes, and it is difficult to disentangle which of the two is more distortionary.

${ }^{31}$ Essentially, the same picture emerges looking at the respective impulse responses for TSELF (see Figure 17 in the Appendix).

${ }^{32}$ See for example the discussion in Kollintzas et al. (2012). 


\section{Appendix}

\section{Additional stylized facts}

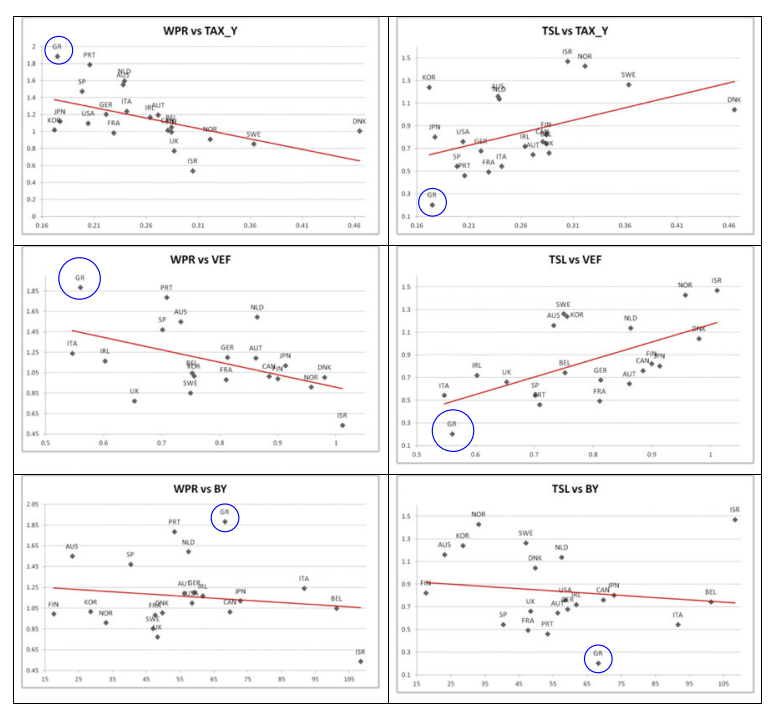

Fig. 9 Public finances. Note: (i) Median values (maximum time span 1970-2010) and (ii) the red line is the linear regression line

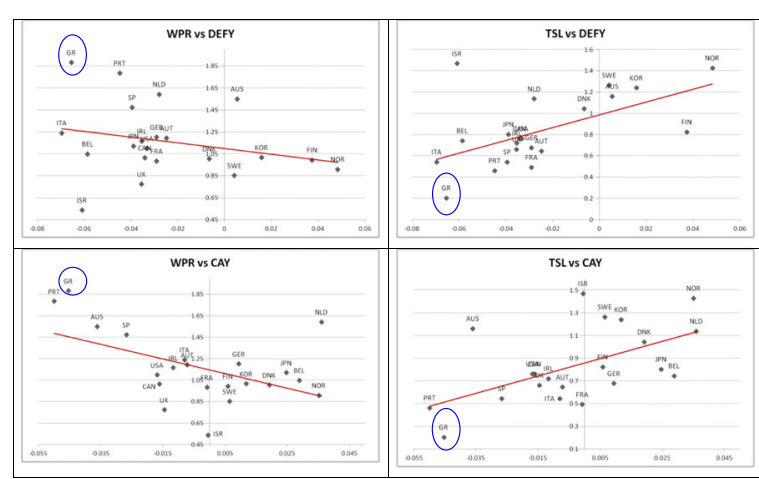

Fig. 10 Twin deficits. Note: (i) Median values (maximum time span 1970-2010) and (ii) the red line is the linear regression line

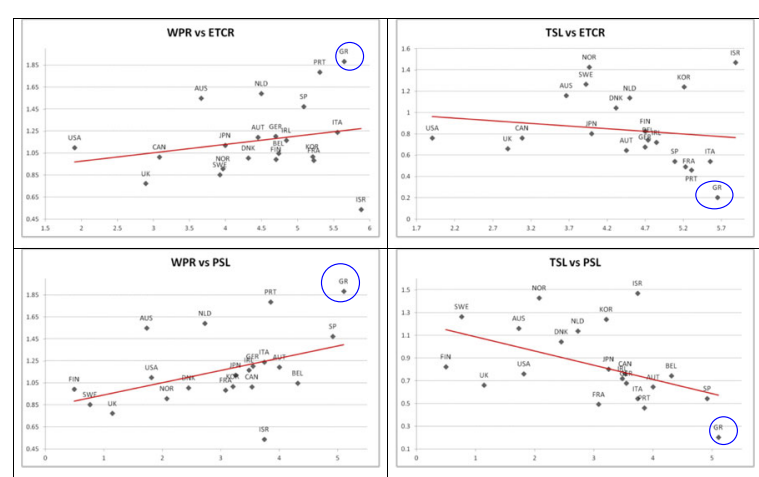

Fig. 11 Competition conditions. Note: (i) Median values (maximum time span 1970-2010) and (ii) the red line is the linear regression line 


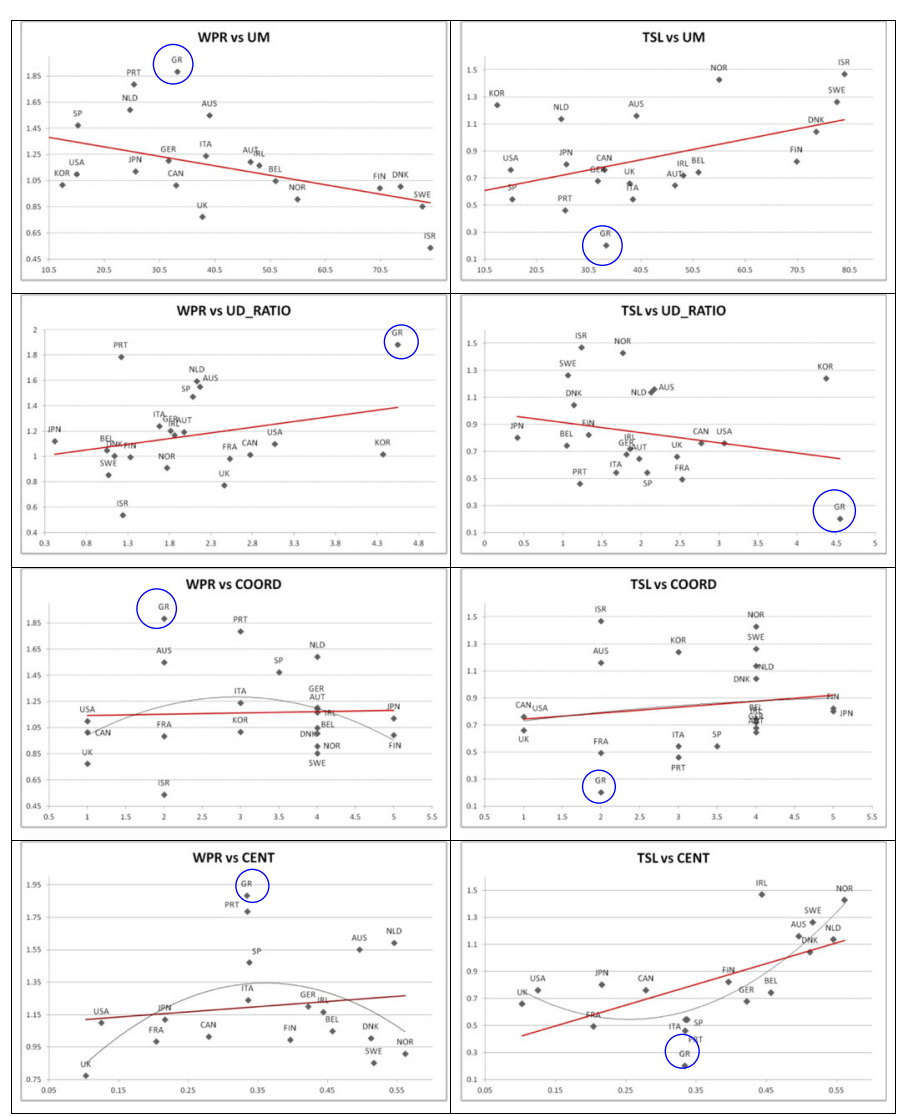

Fig. 12 Labor Institutions. Note: (i) Median values (maximum time span 1970-2010), (ii) the red line is the linear regression line, and (iii) the black curved line is the second-order regression line

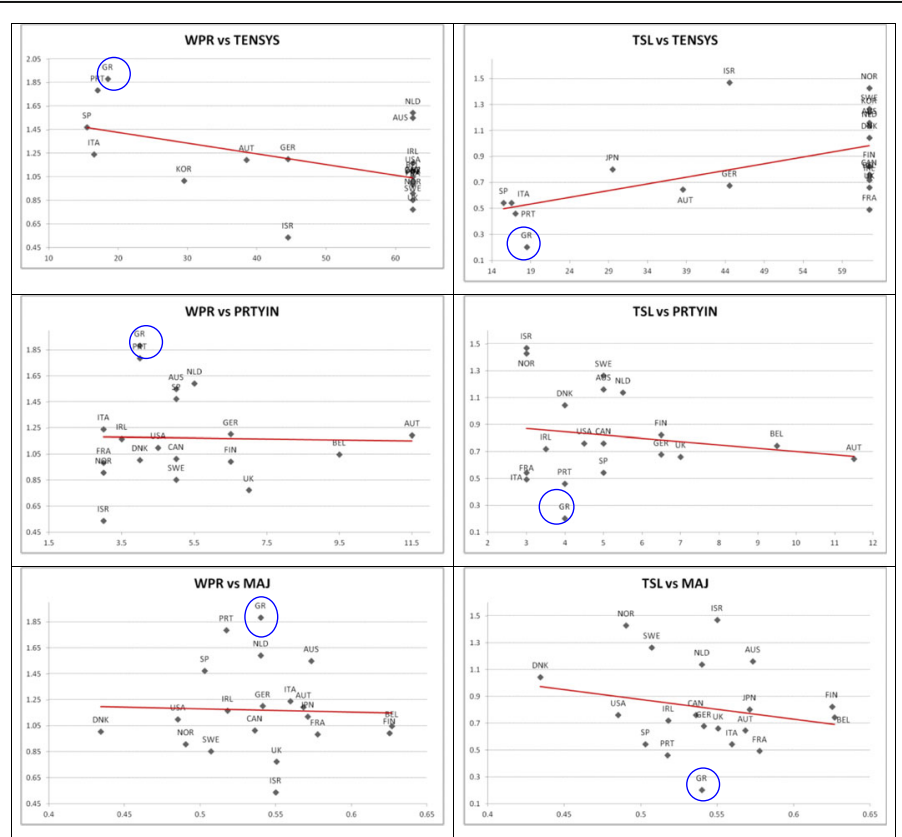

Fig. 13 Political institutions. Note: (i) Median values (maximum time span 1970-2010) and (ii) the red line is the linear regression line 


\section{Additional figures}
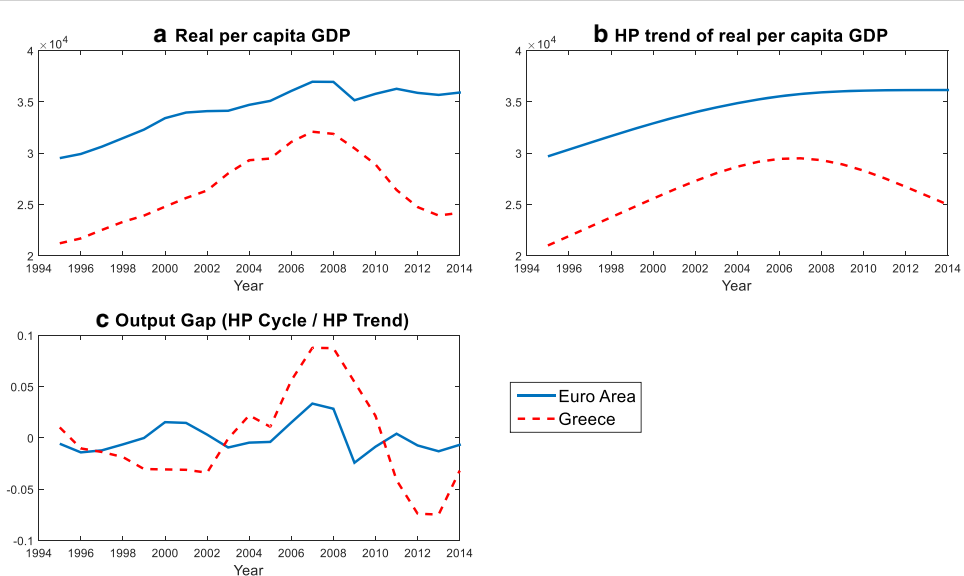

\section{-Euro Area} - - - Greece

Fig. 14 Real per capita GDP in PPP values: Greece vs Euro Area. a Annual data over the period 1995-2014. b Per capita GDP is in constant 2010 prices and constant PPPs and has been detrended with the H-P filter with a smoothing parameter of 100. c Output gap is defined as the ratio of the HP filter cyclical component of real per capita output to the HP trend
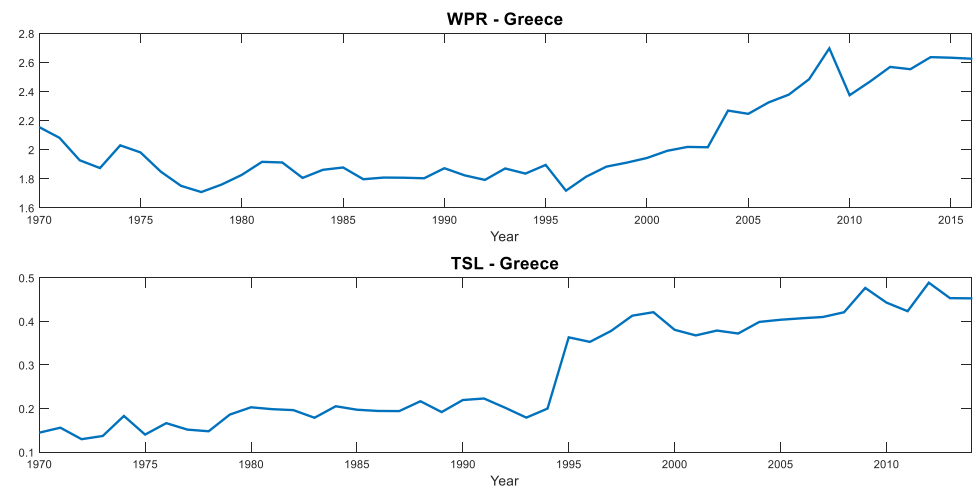

Fig. 15 WPR (1970-2016) and TSL (1970-2014) in Greece

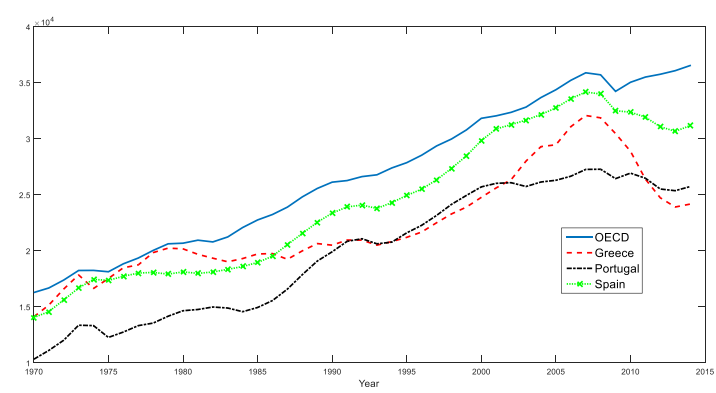

Fig. 16 Real per capita GDP in PPP values in Spain and Portugal vs Greece and OECD. Note: (i) Annual data over the period 1970-2014, (ii) per capita GDP is in constant 2010 prices and constant PPPs 


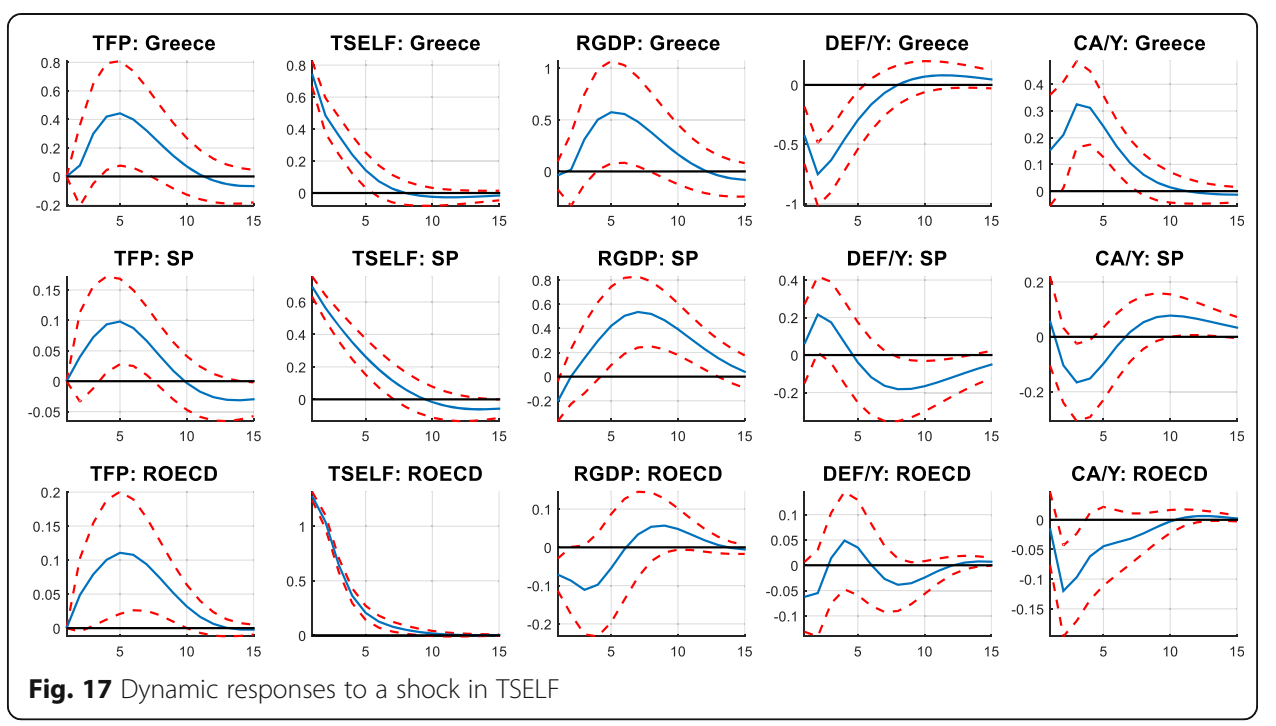

\section{Additional tables}

Table 12 Second moment properties of the HP output gap

\begin{tabular}{llll}
\hline & Standard deviation & Relative volatility & Autocorrelation \\
\hline OECD & 0.015 & 1 & 0.55 \\
GREECE & 0.039 & 2.6 & 0.69 \\
\hline
\end{tabular}

Table 13 Co-movement of the HP output gap between Greece and OECD

\begin{tabular}{lllll}
\hline$t-2$ & $t-1$ & $t$ & $t+1$ & $t+2$ \\
\hline-0.21 & 0.27 & 0.55 & 0.50 & 0.40 \\
\hline
\end{tabular}

(i) Annual data over the period 1970-2014; (ii) per capita GDP is in constant 2010 prices and constant PPPs and detrended with the HP filter with a smoothing parameter of 100; and (iii) output gap is defined as the ratio of the HP filter cyclical component over the corresponding HP trend

Table 14 A comparison of wages: the Greek power company $(\Delta \mathrm{EH})$

\begin{tabular}{lllll}
\hline & $\Delta \mathrm{EH}$ & Public sector & Private sector & EON \\
\hline 2008 & 68,176 & 38,562 & 23,336 & 54,844 \\
2009 & 74,155 & 42,094 & 23,526 & 60,718
\end{tabular}

Source: Greek Budget/ $\triangle \mathrm{EH}$ and EON annual financial statements

Table 15 How TFP is affected by WPR-Greece

\begin{tabular}{llll}
\hline Variable & Coefficient & $t$ statistic & Probability \\
\hline Constant & 1.325345 & 12.15748 & 0.0000 \\
WPR & -0.258381 & -4.849058 & 0.0000 \\
time & 0.007133 & 2.077388 & 0.0454 \\
time $^{2}$ & -0.001022 & -5.026768 & 0.0000 \\
time $^{3}$ & $2.92 \mathrm{E}-05$ & 7.716427 & 0.0000 \\
Adjusted R-squared & 0.892758 & & \\
No. of obs. & 39 & & \\
\hline
\end{tabular}

Estimates are based on OLS 
Table $\mathbf{1 6}$ How TFP is affected by TSL-Greece

\begin{tabular}{llcc}
\hline Variable & Coefficient & $t$ statistic & Probability \\
\hline Constant & 0.739130 & 32.99943 & 0.0000 \\
TSL & 0.516661 & 6.382703 & 0.0000 \\
Adjusted R-squared & 0.511184 & & \\
No. of obs. & 39 & & \\
\hline
\end{tabular}

Estimates are based on OLS

Table $\mathbf{1 7}$ How TFP is affected by WPR-SP

\begin{tabular}{llll}
\hline Variable & Coefficient & $t$ statistic & Probability \\
\hline Constant & 0.879453 & 16.59311 & 0.0000 \\
WPR & -0.047639 & -2.161475 & 0.0341 \\
time & -0.005117 & -1.557608 & 0.1238 \\
time $^{2}$ & 0.000885 & 5.704337 & 0.0000 \\
time $^{3}$ & $-1.61 \mathrm{E}-05$ & -7.038776 & 0.0000 \\
Adjusted R-squared & 0.752159 & & \\
No. of obs. & 75 & & \\
\hline
\end{tabular}

Estimates are based on pooled OLS with robust standard errors

Table 18 How TFP is affected by TSL_SP

\begin{tabular}{lllc}
\hline Variable & Coefficient & t statistic & Probability \\
\hline Constant & 0.763660 & 41.91098 & 0.0000 \\
TSL & 0.419845 & 11.61221 & 0.0000 \\
Adjusted $R$-squared & 0.737985 & & \\
No. of obs. & 63 & & \\
\hline
\end{tabular}

Estimates are based on pooled OLS with robust standard errors

Table 19 How TFP is affected by TSL_SP

\begin{tabular}{llll}
\hline Variable & Coefficient & $t$ statistic & Probability \\
\hline Constant & 0.747308 & 53.20008 & 0.0000 \\
TSL & 0.094088 & 2.177210 & 0.0335 \\
time & 0.013123 & 4.550123 & 0.0000 \\
time $^{2}$ & -0.000275 & -2.095569 & 0.0405 \\
time $^{3}$ & $1.98 \mathrm{E}-06$ & 0.973103 & 0.3345 \\
Adjusted R-squared & 0.923985 & & \\
No. of obs. & 63 & & \\
\hline
\end{tabular}

Estimates are based on pooled OLS with robust standard errors 
Table 20 How TFP is affected by WPR-ROECD

\begin{tabular}{llll}
\hline Variable & Coefficient & t statistic & Probability \\
\hline Constant & 0.565918 & 42.50796 & 0.0000 \\
WPR & 0.090452 & 8.010170 & 0.0000 \\
time & 0.002100 & 1.091721 & 0.2754 \\
time $^{2}$ & 0.000487 & 4.211516 & 0.0000 \\
time $^{3}$ & $-8.29 E-06$ & -4.102892 & 0.0000 \\
Adjusted R-squared & 0.752159 & & \\
No. of obs. & 633 & & \\
\hline
\end{tabular}

Estimates are based on pooled OLS with robust standard errors and country fixed effects

Table $2 \mathbf{1}$ How TFP is affected by TSL-ROECD

\begin{tabular}{llcc}
\hline Variable & Coefficient & t statistic & Probability \\
\hline Constant & 0.580026 & 12.45116 & 0.0000 \\
TSL & 0.310096 & 6.643240 & 0.0000 \\
Adjusted R-squared & 0.227886 & & \\
No. of obs. & 619 & & \\
\hline
\end{tabular}

Estimates are based on pooled OLS with robust standard errors and country fixed effects

Table 22 How TFP is affected by TSL-ROECD

\begin{tabular}{llll}
\hline Variable & Coefficient & t statistic & Probability \\
\hline Constant & 0.700452 & 50.34096 & 0.0000 \\
TSL & -0.039871 & -3.729730 & 0.0002 \\
time & 0.001316 & 0.643384 & 0.5202 \\
time $^{2}$ & 0.000531 & 4.497061 & 0.0000 \\
time $^{3}$ & $-8.81 \mathrm{E}-06$ & -4.373991 & 0.0000 \\
Adjusted R-squared $_{\text {No. of obs. }}$ & 0.907548 & & \\
\hline
\end{tabular}

Estimates are based on pooled OLS with robust standard errors and country fixed effects

\section{Data}

We consider the following countries: Australia, Austria, Belgium, Canada, Denmark, Finland, France, Germany, Greece, Ireland, Israel, Italy, Japan, Korea, Netherlands, Norway, Portugal, Spain, Sweden, the UK, and the USA. Data are yearly and cover a maximum time span from 1970 to 2010. Our main data source for the macroeconomic variables is the OECD Economic Outlook no. 90. Missing values for some specific time periods/variables have been completed from the OECD Economic Outlook nos. 88, 86, and 85 and AMECO. Other data sources are Eurostat, OECD. Stat, the OECD employment and labor market statistics, World Development Indicators (WDI), OECD General Government Accounts, and OECD Revenue Statistics. The political institutions variables are taken from the ICTWSS Databease (Visser (2013)) and The Database of Political Institutions (DPI-2012). Data for education attainment are taken from Barro and Lee (2010). 
Table $\mathbf{2 3}$ List of macroeconomic and other variables

\begin{tabular}{|c|c|c|c|}
\hline Variable & Description & Source & Time span \\
\hline $\begin{array}{l}\text { NGDP } \\
\end{array}$ & Nominal gross domestic product & $\begin{array}{l}\text { OECD Economic Outlook \& } \\
\text { AMECO }\end{array}$ & 1969-2010 \\
\hline RGDP & Real gross domestic product & $\begin{array}{l}\text { OECD Economic Outlook \& } \\
\text { AMECO }\end{array}$ & 1969-2010 \\
\hline PC & Private final consumption expenditure & OECD Economic Outlook & 1970-2010 \\
\hline GDPPPP & $\begin{array}{l}\text { GDP per head, constant prices, constant } \\
\text { PPPs }\end{array}$ & OECD.Stat & 1970-2014 \\
\hline WSSS & Total compensation of employees & OECD Economic Outlook & 1970-2010 \\
\hline WSSE & Compensation rate in the private sector & OECD Economic Outlook & $1970-2010$ \\
\hline GFCF & Gross fixed capital formation & OECD Economic Outlook & 1970-2010 \\
\hline$x$ & Exports of goods and services & OECD Economic Outlook & 1970-2010 \\
\hline YPGT & $\begin{array}{l}\text { Total disbursements of general government } \\
\text { (Total government expenditures) }\end{array}$ & $\begin{array}{l}\text { OECD Economic Outlook } \\
\text { and Eurostat }\end{array}$ & 1970-2010 \\
\hline CGNW & $\begin{array}{l}\text { Government final non-wage consumption } \\
\text { expenditure }\end{array}$ & OECD Economic Outlook & $1970-2010$ \\
\hline CGW & $\begin{array}{l}\text { Government final wage consumption } \\
\text { expenditure }\end{array}$ & $\begin{array}{l}\text { OECD Economic Outlook \& } \\
\text { AMECO }\end{array}$ & 1970-2010 \\
\hline CG & Government final consumption expenditure & OECD Economic Outlook & 1970-2010 \\
\hline DEF & $\begin{array}{l}\text { Government net lending (total government } \\
\text { deficit) }\end{array}$ & OECD Economic Outlook & $1970-2010$ \\
\hline TIND & Taxes on production and imports & OECD Economic Outlook & 1970-2010 \\
\hline TY & Total direct taxes & OECD Economic Outlook & $1970-2010$ \\
\hline CA & $\begin{array}{l}\text { Balance of current transactions with the rest } \\
\text { of the world (Current account balance) }\end{array}$ & AMECO & 1970-2010 \\
\hline TE & Total employment & OECD Economic Outlook & 1970-2010 \\
\hline EE & $\begin{array}{l}\text { Dependent employment - Total economy } \\
\text { (Total employees) }\end{array}$ & OECD Economic Outlook & 1970-2010 \\
\hline EEP & $\begin{array}{l}\text { Dependent employment in the private } \\
\text { sector (Private sector employees) }\end{array}$ & OECD Economic Outlook & $1970-2010$ \\
\hline GE & General government employment & OECD Economic Outlook & $1970-2010$ \\
\hline SE & Total self-employed persons & OECD Economic Outlook & 1970-2010 \\
\hline POP & Working age population $15-64$ & OECD Economic Outlook & 1969-2010 \\
\hline YGAP & $\begin{array}{l}\text { Output gap (gap between actual GDP and } \\
\text { Hodrick-Prescott filter divided by the H-P filter) }\end{array}$ & AMECO & $1970-2010$ \\
\hline UM & $\begin{array}{l}\text { The ratio of employees that are trade union } \\
\text { members divided by the total number of } \\
\text { employees }\end{array}$ & $\begin{array}{l}\text { (i) OECD employment \& } \\
\text { labor market statistics } \\
\text { (ii) ICTWSS database }\end{array}$ & $1970-2010$ \\
\hline POPT25 & $\begin{array}{l}\text { Education attainment - Share in population } \\
\text { over } 25 \text { with Tertiary education }\end{array}$ & Barro and Lee (2010) & $\begin{array}{l}\text { 1970-2010, 5-year } \\
\text { intervals (linear } \\
\text { interpolation used } \\
\text { to fill in missing years) }\end{array}$ \\
\hline PRTYIN & How many years has the party has been in office & DPI2012 & 1975-2010 \\
\hline MAJ & $\begin{array}{l}\text { Margin of majority (fraction of seats held by the } \\
\text { government) }\end{array}$ & DPI2012 & $1975-2010$ \\
\hline TENSYS & $\begin{array}{l}\text { How long has the country been autocratic or } \\
\text { democratic, respectively. }\end{array}$ & DPI2012 & $1975-2010$ \\
\hline DEP_RATIO & $\begin{array}{l}\text { Dependency ratio (people younger than } 15 \\
\text { and older than } 64 \text { as share of working age } \\
\text { population) }\end{array}$ & WDI & 1970-2010 \\
\hline URBAN_POP & Urban population as share of total population & WDI & $1970-2010$ \\
\hline COORD & Index of coordination of wage-setting & ICTWSS database & 1970-2010 \\
\hline CENT & Index of centralization of wage bargaining & ICTWSS database & 1970-2010 \\
\hline UD_public & Union density of public sector workers & ICTWSS database & 1970-2010 \\
\hline UD_private & Union density of private sector workers & ICTWSS database & 1970-2010 \\
\hline
\end{tabular}


Table 23 List of macroeconomic and other variables (Continued)

\begin{tabular}{|c|c|c|c|}
\hline Variable & Description & Source & Time span \\
\hline$\overline{E T C R}$ & $\begin{array}{l}\text { Regulation index in energy, transport and } \\
\text { communication }\end{array}$ & OECD.Stat & 1970-2010 \\
\hline PSL & Regulation index in professional services (legal) & OECD.Stat & 1970-2010 \\
\hline VAT & Standard VAT rate & $\begin{array}{l}\text { Consumption Tax Trends } \\
\text { 2014, OECD Publishing }\end{array}$ & $1970-2010$ \\
\hline TFP & Total factor productivity & AMECO & 1970-2010 \\
\hline$B_{-} Y$ & $\begin{array}{l}\text { General government gross consolidated } \\
\text { debt as share of GDP }\end{array}$ & $\begin{array}{l}\text { OECD Economic Outlook } \\
\& A M E C O\end{array}$ & 1970-2010 \\
\hline
\end{tabular}

Table 24 Own calculations

\begin{tabular}{|c|c|c|c|}
\hline Variable & Description & Calculation & Time span \\
\hline RGDPP & Real per capita GDP & RGDP/POP & 1970-2010 \\
\hline RGDPG & Growth rate of real per capita GDP & LN(RGDPP(t))/ LN(RGDPP(t-1)) & 1970-2010 \\
\hline COMPP & Total compensation of employees in the private sector & WSSS-CGW & $1970-2010$ \\
\hline WP & Compensation rate in the private sector & COMPP/PE & $1970-2010$ \\
\hline WG & Compensation rate in the public sector & CGW/GE & $1970-2010$ \\
\hline WPR & Wage premium & WG/WP & $1970-2010$ \\
\hline TAX_Y & Total tax revenues-to-GDP ratio & $(T I N D+T Y) / N G D P$ & 1970-2010 \\
\hline CGNWY & $\begin{array}{l}\text { Government final non-wage consumption } \\
\text { expenditure-to-GDP ratio }\end{array}$ & CGNW/NGDP & 1970-2010 \\
\hline TL & Effective tax rate on labor income & See Below & 1970-2010 \\
\hline TSELF & Effective tax rate on self-employment income & See Below & 1970-2010 \\
\hline VATR & VAT revenues & Tax revenue statistics, OECD & \\
\hline TVAT & VAT effective tax rate & VATR/(PC-VATR) & 1970-2010 \\
\hline TSL & $\begin{array}{l}\text { Ratio of the effective tax rate on self-employment } \\
\text { income divided by the effective tax rate on labor } \\
\text { income }\end{array}$ & TSE/TL & $1970-2010$ \\
\hline CAY & Current account balance-to-GDP ratio & CA/NGDP & 1970-2010 \\
\hline DEFY & Government net lending-to-GDP ratio & $\mathrm{DEF} / \mathrm{Y}$ & $1970-2010$ \\
\hline UD_RATIO & $\begin{array}{l}\text { Union density of public sector workers to the union } \\
\text { density of private sector workers }\end{array}$ & UD_public/UD_private & 1970-2010 \\
\hline VEF & Ratio of the VAT effective tax rate to the standard VAT rate & TVATNAT & \\
\hline STE & Self-employment over total employment & SE/TE & $1970-2010$ \\
\hline
\end{tabular}

1. For Australia, government final wage consumption is computed as CGW $=$ WSSS WSSE $\times$ EEP, where WSSS is total compensation of employees, WSSE is the compensation rate in the private sector, and EEP is dependent employment in the private sector. Then, the government final non-wage consumption expenditure is computed as CGNW = CG - CGW, where CG is total government consumption.

2. For Germany, total dependent employment, EE, and dependent employment in the private sector, EEP, are respectively computed from the following relationships: WSST $=$ WSSS $/$ EE and WSSE $=($ WSSS - GCW $) / E E P$, where WSST is the compensation rate of the total economy, WSSE is the compensation rate in the private sector, WSSS is total compensation of employees, and GCW is government final wage consumption expenditure. In the case of Germany, the series for WSST and WSSE are given directly in the OECD database and need not to be calculated. For Israel, EE is computed as EE = ET $-\mathrm{SE}$, where ET is total employment and $\mathrm{SE}$ is 
total self-employment. Then, EEP is computed as EEP = EE - GE, where GE is general government employment.

3. For Australia, Austria, Germany, Greece, and Korea, general government employment is computed as GE = EE - EEP, where EE is total dependent employment and EEP is dependent employment in the private sector.

Calculation of effective tax rates on labor income (TL) and self-employment income (TSELF)

The approach of constructing effective tax rates on labor income, capital income, and consumption, follows as close as possible Mendoza et al. (1994). Data are obtained from various editions of the OECD Economic Outlook, OECD Revenue Statistics, OECD Detailed National Accounts and AMECO.

\section{Personal income tax rate}

The personal income tax rate that applies both to labor and capital income of households is:

$$
\tau^{h}=\frac{1100}{\mathrm{WSSS}+\mathrm{YOTH}-2000}
$$

where

1100: taxes on income, profits, and capital gains of individuals

WSSS: compensation of employees

YOTH: net self-employment and property income received by households

2000: total social security contributions

For some countries we have data only on gross self-employment and property income received by households. In this case, in order to obtain YOTH we subtract HCFC. For countries where neither gross nor net self-employment and property income received by households is available, YOTH is approximated by OSPUE - HCFC + PEI, where OSPUE is the gross operating surplus of unincorporated enterprises, HCFC is the consumption of fixed capital of households, and PEI is property income received by households.

Effective tax rate on labor income (TL)

$$
\tau^{L}=\frac{\tau^{h}(\mathrm{WSSS}-2100-2200)+2100+2200+3000}{\mathrm{WSSS}}
$$

where

WSSS: compensation of employees

2100: social security contributions paid by the employees

2200: social security contributions paid by the employers

3000: taxes on payroll and workforce

Effective tax rate on self-employment income (TSELF)

$$
\tau^{\text {self }}=\frac{\tau^{h}(\mathrm{YSE}-2300)+2300}{\mathrm{YSE}}
$$

where

YSE: net self-employment income received by households. This is computed as YSE = YOTH - PEI, where PEI is property income received by households. 
2300: social security contributions paid by the self-employed

Calculations of WPR and TSL for Greece for 2011 and beyond encountered obstacles due to data availability problems:

The effective tax rate on the income of the self-employed, can be calculated until 2014, since some revenue components needed for this calculation in the respective OECD database are not yet provided.

The problems are bigger when it comes to WPR. For some countries, including Greece, for the years after 2010, OECD reports data only for total employment and gives no information on how this is split among general government employment and employment in the private sector. A similar problem occurs at the Eurostat database for Greece, with the series for general government employment stopping at 2011. Note that for most countries there are no large discrepancies between the OECD and Eurostat series. However, for some countries, including Greece, the discrepancies might be large.

In order to update the public sector wage premium for Greece, we work as follows:

We take the series "Employees in Public administration, defence, education, human health and social work activities" from Eurostat, as a measure for employment in the general government. We calculate the growth rate of this series and update our OECD series for general government employment after 2010 assuming that it grows after 2010 at the same rate as the above series from Eurostat. We then consider the Eurostat series for total employees and subtract "employees in public administration, defense, education, human health, and social work activities." This is our measure for private sector employees. We calculate the growth rate of this series and update our OECD series for private sector employees that stops in 2010, assuming that it grows after 2010 as the above series from Eurostat. Data for total compensation of employees and compensation of employees in the general government are taken from OECD Economic Outlook no. 100 and Eurostat, respectively.

Table 25 Data used for the Barro type growth regressions

\begin{tabular}{|c|c|c|c|}
\hline Variable & Description & Calculation & Time span \\
\hline RGDPGO & $\begin{array}{l}\text { Real per capita GDP growth rate at the start } \\
\text { of each period }\end{array}$ & & 1970-2010 \\
\hline IY & Gross fixed capital formation-to-GDP ratio & GFCF/NGDP & $\begin{array}{l}\text { 1970-2010 } \\
\text { In 5-year averages }\end{array}$ \\
\hline$X Y$ & Exports of goods and services-to-GDP ratio & X/NGDP & $\begin{array}{l}\text { 1970-2010 } \\
\text { In 5-year averages }\end{array}$ \\
\hline $\mathrm{SCH}$ & $\begin{array}{l}\text { Average year of total schooling } \\
\text { (age group over } 25 \text { ) at the start of each period }\end{array}$ & Source: Barro and Lee (2010) & 1970-2010 \\
\hline POPG & Population growth & $\mathrm{LN}(\mathrm{POP}(\mathrm{t})) / \mathrm{LN}(\mathrm{POP}(\mathrm{t}-1))$ & $\begin{array}{l}\text { 1970-2010 } \\
\text { In 5-year averages }\end{array}$ \\
\hline CGNWY & $\begin{array}{l}\text { Government final non-wage consumption } \\
\text { expenditure-to-GDP ratio }\end{array}$ & CGNW/NGDP & $\begin{array}{l}\text { 1970-2010 } \\
\text { In 5-year averages }\end{array}$ \\
\hline
\end{tabular}

\section{Acknowledgements}

We have benefited from comments and suggestions by Evi Pappa, Fabrice Collard, George Alogoskoufis, Christos Ghenakos, Yannis Katsoulakos, Nikolaos Mylonidis, and Apostolis Philippopoulos. The views expressed in this paper are those of the authors and do not necessarily reflect those of the Bank of Greece. We would like to thank the anonymous referee and the editor for the helpful remarks.

Responsible editor: Denis Fougère

Funding

Tryphon Kollintzas gratefully acknowledges financial support from the Research Centre of the Athens University of Economics and Business (RC/AUEB), Grant No. ER-2591-01/00-02. 
Availability of data and materials

See data Appendix.

Competing interests

The IZA Journal of Labor Policy is committed to the IZA Guiding Principles of Research Integrity. The authors declare that they have observed these principles.

\section{Publisher's Note}

Springer Nature remains neutral with regard to jurisdictional claims in published maps and institutional affiliations.

\section{Author details}

${ }^{1}$ Athens University of Economics and Business, Athens, Greece. ${ }^{2}$ CEPR, London, UK. ${ }^{3}$ Economic Analysis and Research Department, Bank of Greece, Athens, Greece. ${ }^{4}$ Lancaster University, Lancaster, UK.

Received: 5 September 2017 Accepted: 6 December 2017

Published online: 23 January 2018

\section{References}

Acemoglu D (2006) Modeling inefficient institutions. In: Blundell R, Newey W, Persson T (eds) Advances in Economics and Econometrics, Theory and Applications, Ninth World Congress, vol 1, Chapter 9, Cambridge University Press, pp 341-380

Afonso A, Gomes P (2008) Interactions between private and public sector wages, European Central Bank Working Paper 971

Alesina A, Giavazzi F (2008) The future of Europe: reform or decline. The MIT Press

Alogoskoufis G (1995) The two faces of Janus: institutions, policy regimes and macroeconomic performance in Greece. Econ Policy :149-192

Angelopoulos K, Economides G, Vassilatos V (2011) Do institutions matter for economic fluctuations? Weak property rights in a business cycle model for Mexico. Rev Econ Dyn 14(3):511-531

Angelopoulos K, Philippopoulos A, Vassilatos V (2009) The social cost of rent seeking in Europe. Eur J Poll Economy 25(3):280-299

Ardagna S, Caselli F (2014) The political economy of the Greek debt crisis: a tale of two bailouts. Am Econ J 6(4):291-323

Arellano C, Atkeson A, Wright M (2015) External And Public Debt Crises NBER Working Paper 21456

Artavanis NT, Morse A, Tsoutsoura M (2012) Tax Evasion across industries: soft credit evidence from Greece, Chicago Booth Research Paper No. 12-25; Fama-Miller Working Paper

Barro JR, Lee JW (2010) A new data set of educational attainment in the world, 1950-2010, NBER Working Paper No 15902

Bender K (1998) The central government-private sector wage differential. J Econ Surv 12:177-220

Blanchard O (2004) The economic future of Europe. J Econ Perspect 18(4):3-26

Blanchard O, Perotti R (2002) An empirical characterization of the dynamic effects of changes in government spending and taxes on output. Q J Econ 117(4):1329-1368

Blanchard O (2012) The logic and fairness of Greece's program, iMFdirect - The IMF Blog

Blanchard O (2015), Greece: Past critiques and the path forward, iMFdirect - The IMF Blog

Bosworth B, Kollintzas T (2002) Economic growth in Greece: past performance and future prospects. In: Bryant RC, Garganas NG, Tavlas GS (eds) Greece's economic performance and prospects, Bank of Greece and the Brookings Institution

Bulow J, Kenneth R (2015), The modern greek tragedy, VOX. http://www.voxeu.org/article/modern-greek-tragedy

Campos M, Depalo D, Papapetrou E, Pérez JJ, Ramos R (2017) Understanding the public sector pay gap. IZA J Labor Policy 6:7

Cawson A (1986) Corporatism and political theory. Basil Blackwell, Oxford

Christopoulou R, Monastiriotis V (2014) The Greek public sector wage premium before the crisis: size, selection and relative valuation of characteristics. Br J Ind Relat 52:579-602

Christopoulou R, Monastiriotis V (2016) Public-private wage duality during the Greek crisis. Oxf Econ Pap 68(1):174-196

Conway P, Nicoletti G (2006) Product market regulation in the non-manufacturing sectors of OECD countries: measurement and highlights. OECD Economics Department Working Papers, No. 530, OECD Publishing

De Grauwe P (2013) The political economy of the euro. Annu Rev Political Sci 16:153-170

Depalo D, Giordano R (2011) The public-private pay gap: a robust quantile approach, Banca D'Italia, Working Paper No. 824

Dickens W, Katz LF (1987) Inter-industry wage differences and industry characteristics. In: Lang K, Leonard J (eds) Unemployment and the structure of labor markets. Basil Blackwell, London, pp 48-89

Dimelis S, Kollintzas T, Christodoulakis NM (1997) Economic fluctuations and growth in Greece and Europe (in Greek). IMOP, Athens

Dornbusch R, Draghi M (1990) Public debt management: theory and history. Cambridge University Press, Cambridge

Doxiadis A (2013) The invisible rift (in Greek). Ikaros Publishing

Eichengreen B, Felbman R, Liebman J, von Hagen J, Wyplosz W (2011) Public debts: nuts, bolts and worries, Geneva Reports on the World Economy, 13, International Center for Monetary and Banking Studies (ICMB)

European Commission (2013) Industrial Relations in Europe 2012, European Commission, Directorate -general for employment, social affairs and inclusion

Featherstone K (2008) Varieties of capitalism' and the Greek case: explaining the constraints on domestic reform? GreeSE paper no 11, Hellenic observatory papers on Greece and southeast. LSE, Europe 
Feld LP, Schmidt CM, Schnabel I, Weigert B, Volker W (2015) Greece: no escape from the inevitable, VOX .http://voxeu. org/article/greece-no-escape-inevitable

Forni L, Giordano R (2003) Employment in the public sector, CESifo Working Paper No 1085

Gaju P, Gabor K, Lamo A, Nicolitsa D, Poelhekke S (2010) Inter-industry wage differentials in EU countries: what do cross country time varying data add to the picture? J Eur Econ Assoc 8:478-486

Ghenakos C (2013) Product market reforms in Greece: learning from the past to move forward, in Choupres, M. and Edquist, H. (Eds), What can we learn from economic reforms in Greece and Sweden?, Chapter 4, European Liberal Forum

Giavazzi F, Spaventa L (1988) High public debt: the Italian experience. Cambridge University Press, Cambridge

Gibbons R, Katz LF (1992) Does unmeasured ability explain inter-industry wage differentials? Rev Econ Stud 59:515-535

Giordano R, Depalo D, Pereira M, Eugene B, Papapetrou E, Perez J, Reiss L, Roter M (2011) The public sector pay gap in a selection of euro-area countries. ECB Working Paper No. 1406, European Central Bank

Gnocchi S, Lagerborg A, Pappa E (2016) Do labor market institutions matter for business cycles? J Econ Dyn Control 51: 299-317

Gourinchas PO, Philippon T, Vayanos D (2016) The analytics of the Greek crisis. In: Martin E, Parker JA, (eds) NBER macroeconomics Annual 2016, Volume 31

Gogos SG, Mylonidis N, Papageorgiou D, Vassilatos V (2014) 1979-2001: A Greek great depression through the lens of neoclassical growth theory, Economic Modelling 36, 316-331. https://doi.org/10.1016/j.econmod.2013. 09.031

Gregory RG, Borland J (1999) Recent developments in public sector labor markets. In: Ashenfelter O, Card D (eds) Handbook of labor economics, vol Volume III. Elsevier Science Publishers, Amsterdam

Gross D (2013) Foreign debt versus domestic debt in the euro area. Oxf Rev Econ Policy 29(3):502-517

Hallerberg M, Strauch R, Von Hagen J (2009) Fiscal governance in Europe. Cambridge University Press, Cambridge

Hallerberg M, Von Hagen J (1999) Electoral institutions, cabinet negotiations, and budget deficits in the EU. In: Poterba J, Von Hagen J (eds) Fiscal institutions and fiscal performance. University of Chicago Press, Chicago

House, Christopher L. and Tesar, Linda L. (2015), Greek budget realities: no easy options brookings papers on economic activity, Fall 2015, Symposium on the Greek Debt Crisis, 329-347

loannides YM, Pissarides CA (2015) Is the greek debt crisis one of supply or demand? Brookings Papers on Economic Activity, Fall 2015, Symposium on the Greek Debt Crisis, 349-383

Katz LF, Summers LH (1989) Industry rents: evidence and implications, Brookings Papers on Economic Activity: Microeconomics, 209-275

Kim S, Roubini N (2008) Twin deficit or twin divergence? Fiscal policy, current account, and real exchange rate in the $U$. S. J Int Econ 74(2):362-383

Kollintzas T, Papageorgiou D, Vassilatos V (2012) An explanation of the Greek crisis: the insiders-outsiders society, CEPR Discussion Paper No. 8996

Kollintzas T, Papageorgiou D, Vassilatos V (2017) Market and political power interactions in Greece: a theory, Eur J Pol Econ (In Press, Accepted Manuscript, Available online 14 July 2017. https://doi.org/10.1016/j.ejpoleco.2017.07.003

Kontopoulos Y, Perotti R (1999) Government fragmentation and fiscal policy outcomes: evidence from OECD countries. In: Poterba J, Von Hagen J (eds) Fiscal institutions and fiscal performance. Chicago University Press, Chicago

Leounakis N, Sakellaris P (2014) Greek economic growth since 1960, AUEB, Department of Economics Working Paper Series 16-2014

Lindbeck A, Snower D (2001) Insiders versus outsiders. J Econ Perspect 15(1):165-188

Love I, Zicchino L (2006) Financial development and dynamic investment behavior: evidence from panel VAR. Q Rev Econ Finance 46(2):190-210

Lygeros S (2012) From kleptocracy to bankruptcy, Patakis Editions (in Greek)

Manasse P (2015) What went wrong in Greece and how to fix it: lessons for Europe from the Greek crisis, VOX, 12 June 2015. http://voxeu.org/article/what-went-wrong-greece-and-how-fix-it

Mendoza E, Razin A, Tesar L (1994) Effective tax rates in macroeconomics: cross country estimates of tax rates on factor incomes and consumption. J Monet Econ 34:297-323

Michas T (2011) Putting politics above markets: historical background to the Greek crisis, Cato Institute Working Paper No 5

Milesi-Ferretti GM (2004) Good, bad, or ugly? On the effects of fiscal rules with creative accounting. J Public Econ 88:377-394

Mink M, De Haan J (2013) Contagion during the Greek sovereign debt crisis. J Int Money Financ 34:102-113

Mody A (2015) A programme for Greece: follow the IMF's research, VOX. http://www.voxeu.org/article/programmegreece-follow-imf-s-research

Molina O, Rhodes M (2007) The political economy of adjustment in mixed market economies: a study of spain and italy. In: Hancke B, Rhodes M, Thatcher M (eds) Beyond Varieties of Capitalism, Oxford University Press

Pérez JJ, Aouriri M, Campos MM, Celov D, Depalo D, Papapetrou E, Pesliakaite J, Ramos R, Rodríguez-Vives M (2016) The fiscal and macroeconomic effects of government wages and employment reform, ECB Occasional Paper Series No 176 / August 2016, European Central Bank

Phelps ES (2015) Project syndicate, September 4, 2015. https://www.project-syndicate.org/commentary/foundation-ofgreeces-failed-economy-by-edmund-s-phelps-2015-09?barrier=accessreg

Reinhart CM, Trebesch C (2015) The pitfalls of external independence: Greece, 1829-2015 Brookings Papers on Economic Activity, Fall 2015, Symposium on the Greek Debt Crisis, 307-328

Reinhart CM, Rogoff KS (2010) Growth in a Time of Debt. Am Econ Rev 100(2):573-78. doi:https://doi.org/10.1257/aer. 100.2.573

Sargent J (1985) Corporatism and the European Community. In: Grant W (ed) The political economy of corporatism. Macmillan, London

Schmitter P (1977) Corporatism and policy-making in contemporary Western Europe. Sage Publications, London

Schneider F, Buehn A (2013) Estimating the size of the shadow economy: methods, problems and open questions, CESifo working paper series 4448. CESifo Group, Munich 
Schumacher J, Weder di Mauro B (2015) Diagnosing Greek debt sustainability: why is it so hard?, Brookings Papers on Economic Activity, Fall 2015, Symposium on the Greek Debt Crisis, 279-305

Sondermann D (2012) Productivity in the euro area: any evidence of convergence?, European Central Bank, Working Paper Series No 1431

Velasco A (1999) Debts and deficits with fragmented fiscal policymaking. In: Poterba J, Von Hagen J (eds) Fiscal institutions and fiscal performance. University of Chicago Press, Chicago

Visser J (2013) ICTWSS: Database on institutional characteristics of trade unions, wage setting, state intervention and social pacts in 34 countries between 1960 and 2012, Amsterdam Institute for Advanced Labor Studies (AIAS), University of Amsterdam, Version 4 - April 2013

Von Hagen J, Harden I (1994) Budget processes and commitment to fiscal discipline. Eur Econ Rev 39:771-779

Vourvachaki E (2013) Labor market reforms in Greece. In: Choupres M, Edquist H (eds) What can we learn from economic reforms in Greece and Sweden?, Chapter 2, European Liberal Forum

Zettelmeyer J, Trebesch C, Gulati M (2013) The Greek debt restructuring: an autopsy. Econ Policy 28(75):513-569

Submit your manuscript to a SpringerOpen ${ }^{\circ}$ journal and benefit from:

- Convenient online submission

- Rigorous peer review

- Open access: articles freely available online

- High visibility within the field

- Retaining the copyright to your article

Submit your next manuscript at $\gg$ springeropen.com 